\title{
CRISPR elements provide a new framework for the genealogy of the citrus canker pathogen Xanthomonas citri pv. citri
}

Kwanho Jeong ${ }^{1}$, Alejandra Muñoz-Bodnar ${ }^{1,2}$, Nathalia Arias Rojas', Lucie Poulin 1,3, Luis Miguel Rodriguez-R 1,4, Lionel Gagnevin ${ }^{1,5}$, Christian Vernière ${ }^{5,6}$, Olivier Pruvost $^{5}$ and Ralf Koebnik ${ }^{1 *}$ (D)

\begin{abstract}
Background: Xanthomonads are an important clade of Gram-negative bacteria infecting a plethora of economically important host plants, including citrus. Knowledge about the pathogen's diversity and population structure are prerequisite for epidemiological surveillance and efficient disease management. Rapidly evolving genetic loci, such as Clustered Regularly Interspaced Short Palindromic Repeats (CRISPR), are of special interest to develop new molecular typing tools.

Results: We analyzed CRISPR loci of 56 Xanthomonas citri pv. citri strains of world-wide origin, a regulated pathogen causing Asiatic citrus canker in several regions of the world. With one exception, 23 unique sequences built up the repertoire of spacers, suggesting that this set of strains originated from a common ancestor that already harbored these 23 spacers. One isolate originating from Pakistan contained a string of 14 additional, probably more recently acquired spacers indicating that this genetic lineage has or had until recently the capacity to acquire new spacers. Comparison of CRISPR arrays with previously obtained molecular typing data, such as amplified fragment length polymorphisms (AFLP), variable-number of tandem-repeats (VNTR) and genome-wide single-nucleotide polymorphisms (SNP), demonstrated that these methods reveal similar evolutionary trajectories. Notably, genome analyses allowed to generate a model for CRISPR array evolution in X. citri pv. citri, which provides a new framework for the genealogy of the citrus canker pathogen.
\end{abstract}

Conclusions: CRISPR-based typing will further improve the accuracy of the genetic identification of $X$. citri pv. citri outbreak strains in molecular epidemiology analyses, especially when used concomitantly with another genotyping method.

Keywords: Molecular typing, Genetic diversity, Clustered regularly interspaced short palindromic repeats, Variable numbers of tandem repeats, Spoligotyping, Epidemiology, Phylogeny, Evolution, Xanthomonas citri pv. citri

\section{Background}

Xanthomonads are a large genus of Gram-negative, plant-associated gamma-proteobacteria that shows a high degree of host plant specificity. Pathogenic members of the genus cause diseases on over 300 host plants [1]. Many of these bacteria cause significant yield losses of economically important crops, such as cereals,

\footnotetext{
* Correspondence: Ralf.Koebnik@ird.fr

${ }^{1} \mathrm{IRD}$, Cirad, Université de Montpellier, IPME, Montpellier, France

Full list of author information is available at the end of the article
}

solanaceous and brassicaceous plants [2]. They cause a variety of symptoms, including necrosis, cankers, spots, and blight, and they affect different parts of the plant, including leaves, stems, and fruits [3]. One of the most important diseases caused by Xanthomonas is citrus canker, which results in significant yield losses on susceptible citrus species $[4,5]$. Citrus canker does not only reduce fruit quality and yield but also triggers immediate quarantine restrictions, thus increasing its impact on economy by disrupting trade and implementation of costly eradication programs $[5,6]$. 
Citrus canker is commonly used as a generic term that includes two diseases of citrus caused by strains of Xanthomonas citri. Asiatic citrus canker, which is caused by $X$. citri pv. citri (synonyms, X. citri subsp. citri and $X$. axonopodis pv. citri), is prevalent worldwide and causes major outbreaks. South American citrus canker, which is caused by $X$. citri pv. aurantifolii (synonym, Xanthomonas fuscans subsp. aurantifolii), is geographically restricted to a few South American countries with minor agricultural significance and is very uncommonly isolated from naturally infected citrus [5]. Two other xanthomonads, X. citri pv. bilvae and Xanthomonas euvesicatoria pv. citrumelonis, were reported as citrus pathogens but they produce necrotic spots rather than canker-like lesions and are considered minor pathogens [7-10]. Both canker-causing pathovars were further subdivided into pathotypes (i.e. groups of strains differing in host range within the Citrus genus). Three ( $\mathrm{A}, \mathrm{A}^{*}$ and $\mathrm{A}^{\mathrm{w}}$ ) and two (B and $\mathrm{C}$ ) pathotypes are recognized within $X$. citri pv. citri and $X$. citri pv. aurantifolii, respectively [11-13].

Due to the enormous economic impact, molecular DNA-based methods were developed to rapidly identify and type strains of bacteria associated with citrus canker, including RFLP (restriction fragment length polymorphism), AFLP (amplified fragment length polymorphism), and rep-PCR (repetitive element-polymerase chain reaction) [14-17]. However, these approaches suffered from technical challenges, problematic reproducibility and/or limited comparability. An accurate understanding of the phylogeny and evolution and proper identification of $X$. citri pv. citri strains was achieved through a genome sequencing approach, referred to as next generation sequencing (NGS), which facilitated the genome-wide analysis of evolutionary events in a set of $43 X$. citri pv. citri strains [18]. However, robust and high-resolution genotyping methods, which are less costly, easy to perform and which offer good reproducibility and portability are still required for routine outbreak investigations. Two robust genotyping methods targeting tandem repeats (MLVA; multilocus variable-number of tandem-repeats [VNTR] analysis) suitable for analyses at different evolutionary scales have been developed for X. citri pv. citri [19-21]. Minisatellite-based typing (MLVA-31) and microsatellite-based typing (MLVA-14) are suited for global and local epidemiological analyses, respectively.

Clustered regularly interspaced short palindromic repeats (CRISPRs) constitute a family of DNA repeat sequences, which are widely distributed among Archaea and Bacteria [22-24]. This genetic locus consists of highly conserved DNA repeats that are interspersed by unique, similarly sized spacers, which are acquired from alien DNA elements such as bacteriophages or conjugative plasmids (Fig. 1). CRISPR repeats and spacers form rapidly evolving arrays that can contain up to 100 or even more spacer/repeat units [25, 26]. Typically, CRISPR loci are associated with a conserved cas (CRISPR-associated sequence) gene cluster [27], which functions in the acquisition of new spacers and in the protection against subsequent phage infection. Among the cas genes, cas1 is the only gene which is present in almost all known CRISPR/Cas systems and can therefore be considered as the best marker for CRISPR/Cas systems [28, 29]. Once integrated into the CRISPR array, newly acquired spacers interfere with subsequent infection by DNA elements that carry a matching sequence in their genetic repertoire. Thus, CRISPR/Cas systems function as an adaptive microbial immune system. Notably, new spacers become almost always introduced at the same side of the locus close to the leader sequence; thus, the CRISPR array grows at the proximal end [30-32].

Making use of the polymorphisms in the CRISPR locus, a typing method has been developed for mycobacteria called "spoligotyping" (for spacer oligonucleotide typing) [33, 34]. Spoligotyping is a technique for the identification and analysis of polymorphisms in certain types of spacer/repeat units of CRISPR loci. A PCRbased reverse-line hybridization blotting technique is used to monitor the genetic diversity at CRISPR loci. This method turned out to be extremely useful for routine assays in clinical laboratories as well as for molecular epidemiology, evolutionary and population genetics since it is a fast, robust and cost-effective genotyping method complementary to more traditional fingerprinting techniques. More recently, a new spoligotyping

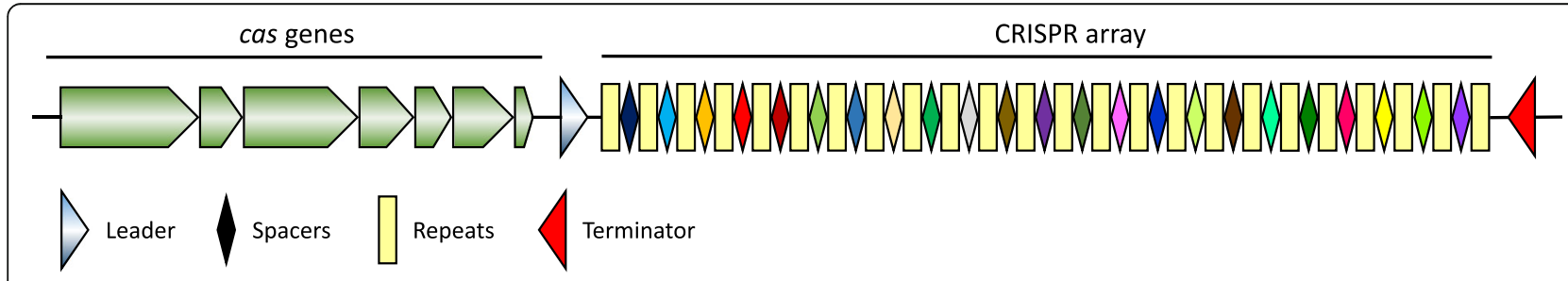

Fig. 1 Schematic representation of the $X$. citri pv. citri CRISPR/Cas locus. Conserved repeats are shown as yellow rectangles, spacers are represented by diamonds in different colors and the leader with the presumed promoter and the terminator region are represented by a blue and a red triangle, respectively. Genes of the cas gene cluster are schematically represented by green arrows. Genetic elements are not drawn to scale 
method based on microbeads was proposed for $\mathrm{Myco-}$ bacterium tuberculosis and Salmonella enterica [35, 36], thus further increasing the throughput and the amount of data that can be queried in internet-accessible databases [37, 38].

CRISPR-based molecular typing did not stay restricted to human pathogens such as Corynebacterium diptheriae, Escherichia coli, Legionella pneumophila, M. tuberculosis, Porphyromonas gingivalis, S. enterica, group A Streptococcus and Yersinia pestis [39]. Polymorphisms in CRISPR arrays were first reported for rice-pathogenic xanthomonads [40, 41]. It was noted that the CRISPR region of rice-pathogenic Xanthomonas oryzae evolves very rapidly and thus provides one of the most striking records of differentiation among bacterial isolates originating from different geographic areas. However, the first applications for plant-pathogenic bacteria were reported for Erwinia amylovora, the causal agent of fire blight, which can affect most members of the Rosaceae family [42, 43]. CRISPR array polymorphisms in this highly homogeneous species allowed clustering representative strains from a worldwide collection into well-defined, evolutionary related groups that reflected their geographic origins and the host plants from which they were isolated. Recently, CRISPR typing combined with VNTR analysis was applied for the first time to strains of Xanthomonas infecting strawberry [44]. Importantly, CRISPR spacer analysis and MLVA of strawberryinfecting Xanthomonas fragariae displayed a congruent population structure, in which two major groups and a total of four subgroups were revealed. Results from this work suggested that the two main groups are responsible for the worldwide expansion of the angular leaf spot disease on strawberry plants.

Here, we describe the CRISPR loci from a representative set of $X$. citri pv. citri strains in order to develop a robust and cost-effective molecular typing method that complements other typing tools, such as MLVA. Since CRISPR loci offer the advantage of building evolutionary scenarios based on time-resolved acquisition and loss of spacers, analysis of $X$. citri pv. citri CRISPR arrays give new insight into the phylogeny and worldwide epidemic of this important plant pathogen.

\section{Results}

PCR screening of $X$. citri strains for the presence of the cas 1 gene

In order to elucidate whether CRISPR/Cas loci are widespread among strains of $X$. citri pv. citri, we first screened our strain collection $(n=56)$ as well as a citruspathogenic $X$. citri pv. bilvae strain for the presence of cas1, the most conserved cas gene, by conventional PCR using cas1-specific primers. A DNA fragment of approximately $220 \mathrm{bp}$ corresponding to the cas 1 gene was amplified from all 56 X. citri pv. citri strains (Additional file 1: Figure S1), indicating that these strains may possess a CRISPR/Cas locus of potential use for molecular typing. However, the $X$. citri pv. bilvae strain (NCPPB 3213) was negative in the PCR screen, suggesting that the cas1 gene may not be conserved in the pathovar bilvae (Additional file 1: Figure S1).

\section{PCR screening of $X$. citri strains for the presence of a CRISPR locus}

All 57 strains were then subjected to PCR amplification of the complete CRISPR locus, using leader- and terminator-specific primers. As expected, PCR products were obtained for all of the $X$. citri pv. citri strains, most of which varied in size between $500 \mathrm{bp}$ and $1400 \mathrm{bp}$ depending on the strain (Additional file 2: Figure S2). These different sizes, probably corresponding to different numbers of spacer/repeat units, indicated that differential deletion and/or acquisition events had occurred. However, for five $X$. citri pv. citri strains, a weak signal corresponding to a DNA fragment of approximately $3500 \mathrm{bp}$ was detected, indicating the presence of an exceptionally large CRISPR locus (Additional file 2: Figure S2, lanes 19, 20, 33, 49 and 50).

On the other hand, no DNA amplification occurred when using DNA of the $X$. citri pv. bilvae strain NCPPB 3213, which was also negative for cas1 (Additional file 1: Figure S1). This result suggested that either NCPPB 3213 does not have a CRISPR/Cas system or that the leader and/or terminator sequences are too distant and do not allow annealing of the used PCR primer(s). We therefore scrutinized the draft genome sequence of strain NCPPB 3213 (NCBI BioProject PRJEB7165) for the presence of cas genes or the CRISPR array, using the CRISPRCasFinder website. This search did not provide evidence that this strain of $X$. citri pv. bilvae would possess this type of CRISPR/Cas immunity system. For these reasons, strain NCPPB 3213 was excluded from further analyses.

In summary, these results suggest that most, if not all, $X$. citri pv. citri strains possess a CRISPR/Cas system, which evolved sufficient diversity due to the acquisition and/or loss of spacer/repeat units, thus allowing the development of a spacer-based typing scheme.

\section{PCR screening of $X$. citri strains for the presence of an IS element in CRISPR loci}

For five strains of $X$. citri pv. citri (LB302, LB305, LG097, LG115, and NCPPB 3608), a DNA fragment of large molecular mass was weakly amplified using primers flanking the CRISPR array. Because we had access to draft genome sequences of most of these strains, we checked for the presence of CRISPRs loci using CRISPRCasFinder. For each strain, two contigs were predicted to contain an array 
of spacers and repeats, with one contig harboring four to five repeats of the leader-proximal end (spacers Xcc_23 to Xcc_20) and another contig harboring 16 to 20 repeats of the terminator-proximal end (spacers Xcc_20 to Xcc_01) (Additional file 3: Figure S3, Additional file 4: Figure S4 and Additional file 5: Figure S5). Notably, all spacer/repeat arrays were found at the ends of the contigs, suggesting that genome assembly was not complete due to the repetitive character of the sequence or due to other factors. Indeed, scrutiny of the contig ends allowed to identify a short inverted repeat, as typically found at the extremities of an IS element. When analyzing the draft genome sequence of NCPPB 3608, we found these inverted repeats 42 times, always located at the end of contigs, further supporting the hypothesis of an IS element insertion in the CRISPR locus (Additional file 3: Figure S3, Additional file 4: Figure S4 and Additional file 5: Figure S5). BLASTN searches identified similar inverted repeats at the extremities of annotated IS elements in the genome of Ralstonia solanacearum strain Po82 (GenBank accession number CP002820). The IS Finder database identified this IS element as ISRso19, which belongs to the IS family IS21.

Using the full-length ISRso19 element as a query, we found a single contig in the draft genome of NCPPB 3608 with $72 \%$ sequence identity, CCWG01000056.1, encompasing most of the IS element. Based on sequence information from the $X$. citri pv. citri and $R$. solanacearum IS elements, we designed PCR primers to amplify the flanking spacer/repeat units. All five strains that resulted in PCR amplification of a large band of weak intensity (LB302, LB305, LG097, LG115 and NCPPB 3608) were evaluated for the presence of the IS element in the CRISPR locus (Additional file 6: Figure S6). PCR with primer combinations Leader_fw and IS-1_rev and IS-2_ fw and Spacer\#18_rev resulted in the amplification of a DNA fragment of approximately $800 \mathrm{bp}$ and $750 \mathrm{bp}$, respectively, for strains LB302, LB305, LG115 and NCPPB 3608. In contrast, the amplicon of strain LG097 was slightly larger with primer combination Leader_fw and IS-1_rev and no specific amplification occured with primer combination IS-2_fw and Spacer\#18_rev (Additional file 6: Figure S6). These results suggested that strains LB302, LB305, LG115 and NCPPB 3608 contain an IS element between spacers Xcc_23 and Xcc_18 while strain LG097 might not possess spacer Xcc_18.

Sequencing of these DNA fragments confirmed that strains LB302, LB305, LG115 and NCPPB 3608 contain an IS element at exactly the same position between spacers Xcc_21 and Xcc_20 (Additional file 3: Figure S3 and Additional file 4: Figure S4). Sequencing of the amplicon from strain LG097 revealed the presence of spacers Xcc_23, Xcc_22, Xcc_20, Xcc_19 and Xcc_18 (except for $4 \mathrm{bp}$ at the site of the IS element insertion) between the leader region and the IS element
(Additional file 5: Figure S5). To amplify the opposite site of the IS element insertion in LG097, we performed a PCR with primers IS-2_fw and Terminator_rev. DNA sequencing confirmed that an IS element had inserted in spacer Xcc_18 in strain LG097 (Additional file 5: Figure S5).

\section{Analysis of CRISPR spacers and spoligotypes}

CRISPR loci from all $56 X$. citri pv. citri strains were completely sequenced and patterns of presence and absence of spacers were analyzed. Altogether, 25 different patterns (spoligotypes) were found (Fig. 2). A total of 37 distinct spacers were identified among the $56 \mathrm{X}$. citri pv. citri strains. Most strains contain between 8 and 23 spacer/repeat units, corresponding to spacers Xcc_01 to Xcc_23. Strain CFBP 2911 was exceptional in that it contains 14 unique spacers (Xcc_24 to Xcc_37), bringing the total number of spacer/repeat units of this strain to 31 (Fig. 2). This strain was the only one that contains spacers Xcc_24 to Xcc_37. The size of spacers varies between $34 \mathrm{bp}$ and $37 \mathrm{bp}$ (Table 1). Except for strain CFBP 2911, spacer Xcc_23 was likely the most recently acquired spacer, which is conserved in most of the 56 strains (except for LG117 and NCPPB 3615). Most of the 25 spoligotype patterns likely evolved by the deletion of a single spacer/repeat unit although simultaneous deletion of adjacent spacer/repeat units probably occurred as well, as suggested by the absence of intermediate CRISPR structures (Fig. 2). Deletion of spacer/repeat units appeared to be random.

In order to decipher the origin of the 37 spacers, the NCBI GenBank was queried for similar sequences using the BLASTN algorithm. As expected, spacers Xcc_23 to Xcc_01 had hits in several genome sequences of $X$. citri pv. citri, reflecting their high conservation in this pathovar of the species $X$. citri.

Using stringent thresholds (E-value smaller than 0.1 and at least $90 \%$ coverage of the query sequence), we found significant matches between eight spacers and sequences from Xanthomonas-specific bacteriophages, which were however restricted to the 14 unique spacers of strain CFBP 2911 (Table 1; Additional file 7: Table S1). The other six spacers among the 14 unique CFBP 2911 spacers did not have any significant hit. Among the Xanthomonas bacteriophages, we found one that had been shown to cause lytic infections of some strains of $X$. citri pv. citri (bacteriophage CP1, GenBank accession number AB720063) [45]. Bacteriophage phi Xc10 (GenBank accession number MF375456) can infect $X$. citri pv. citri, but also Xanthomonas citri pv. glycines and Xanthomonas campestris pv. campestris. Three bacteriophages, f30-Xaj (GenBank accession number KU595433), f20-Xaj (GenBank accession number KU595432) and XAJ24 (GenBank accession number KU197013), were isolated from walnut 


\begin{tabular}{|c|c|c|c|c|c|c|c|c|c|c|c|c|c|c|c|c|c|c|c|c|c|}
\hline & & \begin{tabular}{|l|l|}
23 & 22 \\
\end{tabular} & 21 & 20 & \begin{tabular}{l|l}
19 & 18 \\
\end{tabular} & \begin{tabular}{|l|l|}
17 & 16 \\
\end{tabular} & \begin{tabular}{|l|l|}
5 & 15 \\
\end{tabular} & \begin{tabular}{l|l|}
14 & 13 \\
\end{tabular} & \begin{tabular}{|l|l|}
3 & 12 \\
\end{tabular} & 11 & 10 & \begin{tabular}{l|l}
9 & 8 \\
\end{tabular} & \begin{tabular}{l|l}
8 & 7 \\
\end{tabular} & 6 & 5 & 4 & \begin{tabular}{l|l}
3 & 2 \\
\end{tabular} & \begin{tabular}{l|l}
2 & 1 \\
\end{tabular} & Strain & Origin & Pathotype \\
\hline & Spoligotype $1^{*}$ & & I & & & & & & & & & & & & & & & & NCPPB 3608 & India & $A^{w}$ \\
\hline \multirow{3}{*}{\multicolumn{2}{|c|}{ Spoligotype 2}} & & & & & & & & & & & & & & & & & & CFBP 2852 & India & A \\
\hline & & & & & & & & & & & & & & & & & & & JW160-1 & Bangladesh & A \\
\hline & & & & & & & & & & & & & & & & & & & LB100-1 & Seychelles & A \\
\hline \multirow{3}{*}{\multicolumn{2}{|c|}{ Spoligotype 2* }} & & I & & & & & & & & & & & & & & & & LB302 & Florida, USA & $A^{w}$ \\
\hline & & & I & & & & & & & & & & & & & & & & LB305 & Florida, USA & $A^{w}$ \\
\hline & & & I & & & & & & & & & & & & & & & & LG115 & India & $A^{w}$ \\
\hline & Spoligotype 3* & & & & & & & & & & & & & & & & & & LG097 & Bangladesh & A \\
\hline \multirow{3}{*}{\multicolumn{2}{|c|}{ Spoligotype 4}} & & & & & & & & & & & & & & & & & & JF090-8 & Oman & $A^{w}$ \\
\hline & & & & & & & & & & & & & & & & & & & JJ238-10 & Maldives Islands & A \\
\hline & & & & & & & & & & & & & & & & & & & LG100 & India & $\mathrm{A}^{\mathrm{w}}$ \\
\hline & Spoligotype 5 & & & & & & & & & & & & & & & & & & NCPPB 3612 & India & A \\
\hline & Spoligotype 6 & & & & & & & & & & & & & & & & & & NCPPB 3610 & India & A \\
\hline & Spoligotype 7 & & & & & & & & & & & & & & & & & & LG116 & India & $\mathrm{A}^{\mathrm{w}}$ \\
\hline \multirow{3}{*}{\multicolumn{2}{|c|}{ Spoligotype 8}} & & & & & & & & & & & & & & & & & & $\mathrm{C} 40$ & Reunion Island & A \\
\hline & & & & & & & & & & & & & & & & & & & JK004-1 & China & A \\
\hline & & & & & & & & & & & & & & & & & & & LMG 9322 & Florida, USA & A \\
\hline \multirow{4}{*}{\multicolumn{2}{|c|}{ Spoligotype 9}} & & & & & & & & & & & & & & & & & & JK002-10 & Saudi Arabia & $\mathrm{A}^{*}$ \\
\hline & & & & & & & & & & & & & & & & & & & JK002-14 & Saudi Arabia & $\mathrm{A}^{*}$ \\
\hline & & & & & & & & & & & & & & & & & & & JK048 & Saudi Arabia & $\mathrm{A}^{*}$ \\
\hline & & & & & & & & & & & & & & & & & & & JK051 & Saudi Arabia & $\mathrm{A}^{*}$ \\
\hline \multirow{4}{*}{\multicolumn{2}{|c|}{ Spoligotype 10}} & & & & & & & & & & & & & & & & & & JF090-2 & Oman & $\mathrm{A}^{*}$ \\
\hline & & & & & & & & & & & & & & & & & & & JF090-3 & Oman & $\mathrm{A}^{*}$ \\
\hline & & & & & & & & & & & & & & & & & & & JM035-2 & Saudi Arabia & $\mathrm{A}^{*}$ \\
\hline & & & & & & & & & & & & & & & & & & & NCPPB 3607 & India & $\mathrm{A}^{*}$ \\
\hline Spoligotype 11 & 14 new spacers & & & & & & & & & & & & & & 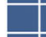 & $\theta$ & 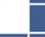 & & CFBP 2911 & Pakistan & $\mathrm{A}^{*}$ \\
\hline \multirow{3}{*}{\multicolumn{2}{|c|}{ Spoligotype 12}} & & & & & & & & & & & & & & & & & & LE020-1 & Ethiopia & $\mathrm{A}^{*}$ \\
\hline & & & & & & & & & & & & & & & & & & & LE003-1 & Ethiopia & $\mathrm{A}^{*}$ \\
\hline & & & & & & & & & & & & & & & & & & & LE032-1 & Ethiopia & $\mathrm{A}^{*}$ \\
\hline & Spoligotype 13 & & & & & & & & & & & & & & & & & & LE065-1 & Ethiopia & $\mathrm{A}^{*}$ \\
\hline \multirow{4}{*}{\multicolumn{2}{|c|}{ Spoligotype 14}} & & & & & & & & & & & & & & & & & & FDC0217 & Brazil & A \\
\hline & & & & & & & & & & & & & & & & & & & FDC1083 & Brazil & A \\
\hline & & & & & & & & & & & & & & & & & & & IAPAR306 & Brazil & A \\
\hline & & & & & & & & & & & & & & & & & & & LC080 & Mali & A \\
\hline \multirow{5}{*}{\multicolumn{2}{|c|}{ Spoligotype 15}} & & & & & & & & & & & & & & & & & & LD007-1 & Mali & A \\
\hline & & & & & & & & & & & & & & & & & & & LE116-1 & Mali & A \\
\hline & & & & & & & & & & & & & & & & & & & LE117-1 & Mali & A \\
\hline & & & & & & & & & & & & & & & & & & & LH037-1 & Senegal & A \\
\hline & & & & & & & & & & & & & & & & & & & NCPPB 3562 & India & A \\
\hline \multirow{4}{*}{\multicolumn{2}{|c|}{ Spoligotype 16}} & & & & & & & & & & & & & & & 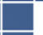 & & & JK143-05 & Thailand & $\mathrm{A}^{*}$ \\
\hline & & & & & & & & & & & & & & & & & & & JK143-09 & Thailand & $\mathrm{A}^{*}$ \\
\hline & & & & & & & & & & & & & & & & & & & $\mathrm{JJ} 238-24$ & Thailand & $\mathrm{A}^{*}$ \\
\hline & & & & & & & & & & & & & & & & 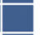 & & & LD071A & Cambodia & $\mathrm{A}^{*}$ \\
\hline & Spoligotype 17 & & & & & & & & & & & & & & & 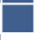 & & & JK143-11 & Thailand & $\mathrm{A}^{*}$ \\
\hline & & & & & & & & & & & & & & & & & & & JS552 & Iran & $\mathrm{A}^{*}$ \\
\hline & & & & & & & & & & & & & & & & & & & JS555 & Iran & $\mathrm{A}^{*}$ \\
\hline & Spoligotype 18 & & & & & & & & & & & & & & 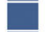 & & & & JS581 & Iran & $\mathrm{A}^{*}$ \\
\hline & & & & & & & & & & & & & & & & & & & JS582 & Iran & $\mathrm{A}^{*}$ \\
\hline & & & & & & & & & & & & & & & & & & & JS584 & Iran & $\mathrm{A}^{*}$ \\
\hline & Spoligotype 19 & & & & & & & & & & & & & & & & & & JJ010-1 & Rodrigues Island & A \\
\hline & Spoligotype 20 & & & & & & & & & & & & & & & & & & JK148-10 & Philippines & A \\
\hline & Spoligotype 21 & & & & & & & & & & & & & & & & & & CFBP 2900 & Japan & A \\
\hline & Spoligotype 22 & & & & & & & & & & & & & & & & & & LG102 & Bangladesh & A \\
\hline & Spoligotype 23 & & & & & & & & & & & & & & & & & & LH001-3 & Pakistan & A \\
\hline & Spoligotype 24 & & & & & & & & & & & & & & & & & 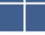 & NCPPB 3615 & India & $\mathrm{A}^{*}$ \\
\hline & Spoligotype 25 & & & & & & & & & & & & & & & & & & LG117 & Bangladesh & A \\
\hline
\end{tabular}

Fig. 2 Spoligotypes of 56 X. citri pv. citri strains. CRISPR arrays are oriented with the leader-proximal spacers on the left side. Identical spacers within the same block are vertically aligned. Detected CRISPR spacers are represented by deep blue boxes, with the identifier of spacers indicated by numbers in the first row. White boxes indicate the absence of the corresponding spacer. Orange boxes indicate the presence of IS elements and the light blue box indicates a variant of spacer Xcc_18 with a deletion of 4 bp due to the IS element insertion. 14 unique spacers are shown as red box for strain CFBP 2911. Spoligotype $2^{*}$ is identical to spoligogtype 2, but contains an IS element between spacers Xcc_20 and Xcc_21

trees and have lytic activity against Xanthomonas arboricola pv. juglandis [46, 47]. All five bacteriophages belong to the order of Causovirales, with CP1 being a member of the Siphoviridae and the others being members of the Podoviridae. Spacer Xcc_35 was also similar to a virulent bacteriophage for Xylella fastidiosa (bacteriophage Prado; Caudovirales; Podoviridae; GenBank accession number
KF626667) with a host range that includes Xanthomonas spp. [48]. Spacer Xcc_31 was also similar to a sequence in the genome of the Ralstonia-related blood disease bacterium R229 (GenBank accession number FR854082), which likely belongs to an integrated prophage and encodes a DNA polymerase A (GenBank accession number CCA83269.1) (Additional file 7: Table S1). 
Table 1 List of spacer sequences of Xanthomonas citri pv. citri identified in the present study and homologous sequences in other organisms

\begin{tabular}{|c|c|c|}
\hline Name & Sequence $\left(5^{\prime} \rightarrow 3^{\prime}\right)$ & Bacteriophage-related homologs \\
\hline Xcc_37* & aggtatggattgcccgccatagggcggatgttgtcg & (Phage from Xanthomonas) \\
\hline Xсc__36 * & tcgctaatcgccaaattgctggagattggecgcgg & Phage from Xanthomonas \\
\hline Xcc_35 * & accatcgaagccgagtacaatggcatgtacgtggag & Phages from Xanthomonas and Xylella \\
\hline Xсc__34 * & ctcatgtactcaaccgtaaactcacgcacgacacg & [Phage from Xanthomonas] \\
\hline Xcc_33 * & accaacgcactggeccgccgagctgacatccacag & Phage from Xanthomonas \\
\hline Xcc_32* & atctgcttgtctagttccaaaatcgccttaaccgg & [Phage from Xanthomonas] \\
\hline Xсc__31* & atcgacggcggcggcatggtgtgggactgccagctg & $\begin{array}{l}\text { Phages from Xanthomonas and Xylella, } \\
\text { prophage in Ralstonia; (Phages from } \\
\text { Burkholderia, Ralstonia and Xylella) }\end{array}$ \\
\hline Xcc_30 * & atcgccagcaagcccatgagcaagggcggctgcgg & Phages from Xanthomonas \\
\hline Xcc_29* & ctcatcaccaccctggagaacgcagcggaaagatgg & No \\
\hline Xcc_28* & gagttcgagggcaagaagaagacgcaggatgaaggg & $\begin{array}{l}\text { Phages from Xanthomonas; (Phages from } \\
\text { Caulobacter and Xylella) }\end{array}$ \\
\hline Xcc_27* & ttgcgtataccatccggeccgaacttctccgagg & $\begin{array}{l}\text { Phages from Xanthomonas; (Phage from } \\
\text { Xanthomonas) }\end{array}$ \\
\hline Xcc_26* & tattaggagacaatatgaatactgcacctaacatg & No \\
\hline Xcc_25 * & tgtagattcggcgaattggatgacaggcgaccgg & Phage from Xanthomonas \\
\hline Xcc_24* & tcttaagagaagctcggatcgtggtttcaaggtcg & No \\
\hline Xcc_23 & aaatgctttcgacgcgcataaagcgctggcgcaggag & No \\
\hline Xcc_22 & ctgttcaagctccgecgectgatccgcttgccgag & Filamentous phage in $X$. citri pv. vignicola \\
\hline Xcc_21 & ctcgggtttcgggatgtgcttcagatctgcgtcg & No \\
\hline Xcc_20 & cgctgcacggatgcgccaggcggcgaggcgatcat & Prophage in X. citri pv. vignicola \\
\hline Xcc_19 & tcgagcgcatcgatgacggtcacccatcccccaatg & No \\
\hline Xcc_18 & gtgccaccgacagcgacgcacgtggacctgcagatc & No \\
\hline Xcc_17 & ctctctcacgccgcgcgtgcgagatcctgcgtgc & No \\
\hline Xcc_16 & gcagactgccgaggccggcatgctggaggggcgcct & Prophage in X. citri pv. phaseoli \\
\hline Xcc_15 & gggttaacaacgecttgaaacggctttgccgcgacgc & No \\
\hline XCc_14 & acgtcttggacctgggtgtggttgctgagatagtca & No \\
\hline Xcc_13 & gccatcatgctttgaatgcgcttacccacggcgaa & No \\
\hline Xcc_12 & gcggatatgtgattagacccttttacgactttcag & No \\
\hline Xcc_11 & atgtcgaaaacgatggecttgacgtcatcgtctgc & $\begin{array}{l}\text { (Phage from Achromobacter); [Phage from } \\
\text { Streptomyces] }\end{array}$ \\
\hline Xcc_10 & ttcgctggcatcggtggatggagccttgcgcttc & (Uncultured Mediterranean bacteriophage) \\
\hline Xcc_9 & tcattgaacccaaggaccacttcgcagggcgact & No \\
\hline Xcc_8 & ttgaccacatgttctctctgtgggaggaaggcac & No \\
\hline Xcc_7 & tgtcgagcgcgcactgctgccgcgatggccggaa & No \\
\hline Xcc_6 & ggctgggagcgttacaagtttgagcagcccgtag & No \\
\hline Xcc_5 & tggttcagggctggaaagacttggatgcccgcatc & No \\
\hline Xcc_4 & ctgactatccctgcataggccacgacctgcgagg & No \\
\hline Xcc_3 & aagaagaccagtctgcggcgtcgcggcatcctgggg & No \\
\hline Xcc_2 & ctgagttcgtcgccgtcccggtcgtctgacgcgt & [Phage from Microbacterium] \\
\hline Xcc_1 & catgccatatgcggcgagatcgcacagcagaaggaa & Prophage in X. citri pv. vignicola \\
\hline
\end{tabular}

*, these spacers were only detected in strain CFBP 2911

Homologs are indicated in round brackets when they match with less stringent search criteria (E-value between 0.1 and 1) (Additional file 7: Table S1). Homologs in square brackets indicate that these are matches with E-values $>1$ (see Discussion) 
Among the conserved 23 spacers, only four had significant matches in the non-redundant GenBank database, all of which corresponded to sequences from other Xanthomonas species or pathovars (Additional file 7: Table S1). Spacers Xcc_22, Xcc_20 and Xcc_01 were similar to sequences in the $X$. citri pv. vignicola strain CFBP 7113. Notably, spacer Xcc_22 matched to locus XcvCFBP7113P_11110, which has been annotated to encode a hypothetical protein. However, BLASTP search of the coding sequence revealed $80 \%$ sequence identity with protein I of the Xanthomonas campestris filamentous bacteriophage $\Phi$ Lf (GenBank accession number AAB88261) [49]. Spacer Xcc_01 matched to locus XcrCFBP7113P_16810 (annotated as hypothetical protein with similarity to the Pfam domain NinB [PF05772; E-value 8.2e-30], which corresponds to the DNA recombination protein NinB of bacteriophage lambda) and spacer Xcc_20 matched to the intergenic region between loci XcvCFBP7113P_16630 and XcvCFBP7113P_16635. All these loci belong to a 29-kb region (GenBank accession number CP022270; 3,740,909 to 3,769,866) that likely corresponds to (remnants of) a prophage. A similar region with $74 \%$ sequence identity over the whole length is present in the genomes of the $X$. citri pv. phaseoli var. fuscans strains (e.g. strain CFBP 6988R, GenBank accession number CP020979, 3,315,711-3,346, 400). Interestingly, spacer Xcc_16 matches to a sequence motif in this region (e.g. locus XcfCFBP6988P_14885 in strain CFBP 6988R, annotated as hypothetical protein). Thus, all spacers that had a hit in the GenBank database derived from bacteriophage or prophage sequences.

\section{Comparison of evolutionary distance trees derived from AFLP and CRISPR genotyping}

We analyzed the distances of 56 X. citri pv. citri strains based on information about the CRISPR locus, which was obtained by conventional PCR and DNA sequencing, and compared them with those from AFLP analyses (Fig. 3). In general, there was a fairly good congruence between the two methods, except for strains LG117 and LH001-3. The 25 spoligotypes of the $56 X$. citri pv. citri strains were classified in 7 groups and 2 singletons. In contrast, AFLP generated 49 haplotypes for the same set of strains (Fig. 3). Both genotyping methods accurately classified strains with respect to the two major pathotypes, $A$ and $A^{*}$, with the few $A^{\mathrm{w}}$ strains strongly linked to the A strains (Fig. 3). However, spoligotypes were found to lack resolution for accurate

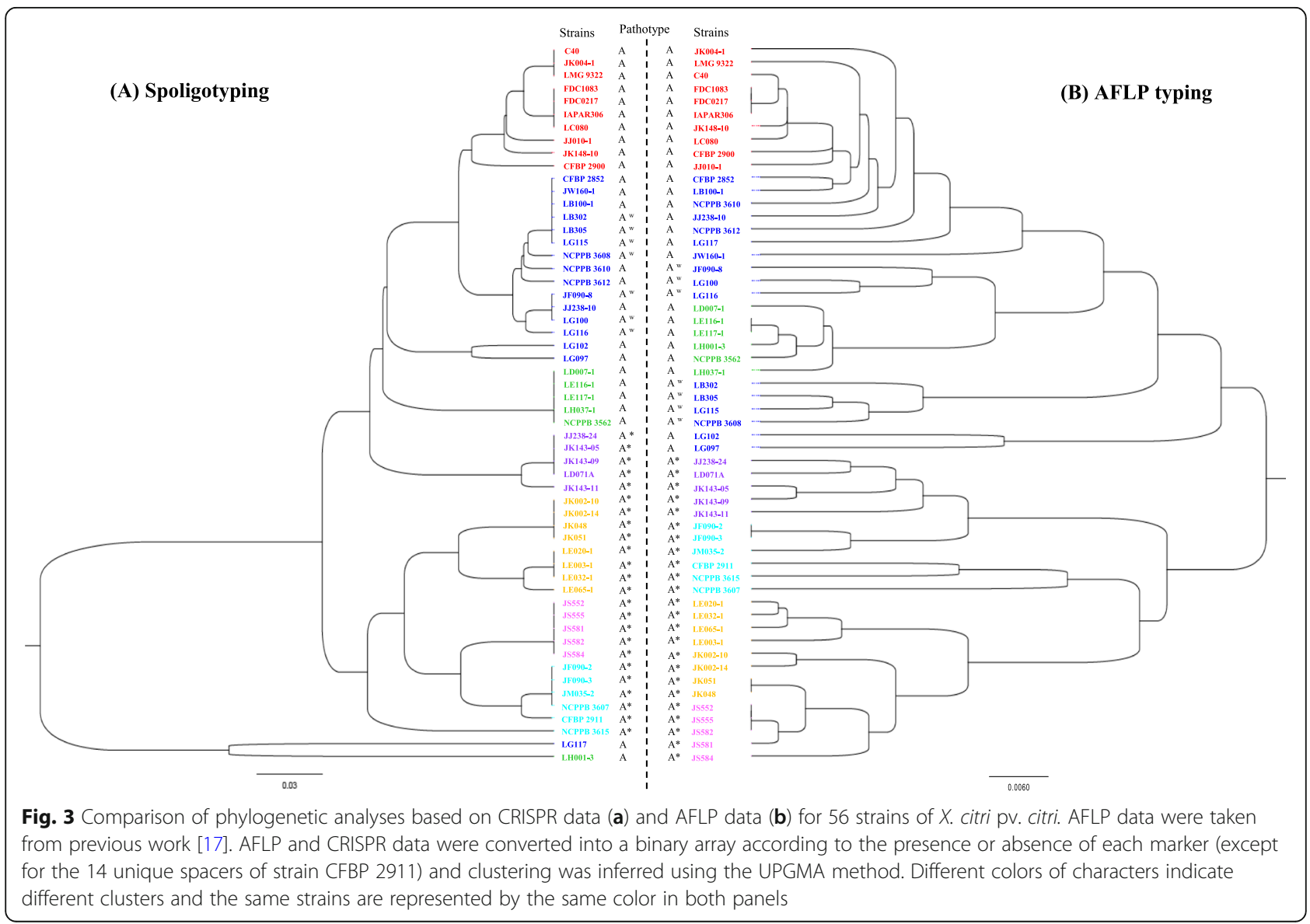


identification of $\mathrm{A}^{\mathrm{w}}$ strains, as in several cases, $\mathrm{A}$ and $\mathrm{A}^{\mathrm{w}}$ strains were found to share identical patterns. Distinction between these strains was only possible by additional evidence. For instance, the presence of an IS element could distinguish some $\mathrm{A}^{\mathrm{w}}$ strains (LB302, LB305, LG115) from A strains (CFBP 2852, JW160-1, LB100-1).

\section{Comparison of the discriminatory power of CRISPR typing} with other genotyping methods

To define the advantage of CRISPR typing tool, we compared the discriminatory power of CRISPR typing with other genotyping methods that have been applied to $X$. citri pv. citri previously [17, 19, 21]. The Mantel pairwise correlation results revealed the highest value between MLVA-31 data and AFLP data $(r=0.590 ; P<0.001)$ (Table 2). When comparing the CRISPR typing method with the other methods, the best correlation was found with AFLP typing, showing a relatively high and significant value $(r=0.467 ; \mathrm{P}<0.001)$ (Table 2). Globally, the genetic distances derived from the four typing methods were highly significantly congruent in almost all cases $(\mathrm{P}<0.001)$, while the distances between microsatellite (MLVA-14) and CRISPR data were less significantly congruent $(P=0.021)$ (Table 2$)$.

\section{Discussion}

The CRISPR locus is an important genetic locus that can be used for bacterial typing in molecular epidemiology analyses [39]. Whereas CRISPR-based typing and comparison of strains has become an established technique for human pathogens, it has remained largely unexplored for plant pathogens [50]. To the best of our knowledge, only a few studies have been published, mostly on a single plant pathogen, E. amylovora [42, 43, 51]. Very recently, two CRISPR loci, one of which displayed sufficient complexity for being used as a strain subtyping technique, were reported from $X$. fragariae [44]. CRISPR data, analyzed from a collection of $55 X$. fragariae strains, yielded a genetic structure in agreement with that derived from MLVA data targeting 27 microsatellites and 9 minisatellites.

Table 2 Mantel test results for the pairwise correlations of genetic distances among 56 strains of Xanthomonas citri pv. citri obtained for four different genotyping methods. Mantel coefficients above the diagonal, $P$ values of Mantel correlation coefficients below the diagonal

\begin{tabular}{lllll}
\hline Genotyping methods & AFLP $^{a}$ & CRISPR & MLVA-14 $^{\text {a }}$ & MLVA-31 $^{a}$ \\
\hline AFLP & - & 0.467 & 0.397 & 0.590 \\
CRISPR & $<0.001$ & - & 0.152 & 0.333 \\
MLVA-14 & $<0.001$ & 0.021 & - & 0.509 \\
MLVA-31 & $<0.001$ & $<0.001$ & $<0.001$ & -
\end{tabular}

a Data for MLVA-14, MLVA-31 and AFLP analyses were taken from previously published datasets $[17,19,21]$
Presence of CRISPR loci in citrus-infecting xanthomonads In the present study, we analyzed 57 strains of $X$. citri for the presence of CRISPR loci. Our results demonstrated that both the cas 1 gene and the CRISPR array are conserved in all 56 strains of $X$. citri pv. citri. However, our PCR screen failed to amplify a cas 1 gene or a CRISPR array in the $X$. citri pv. bilvae strain NCPPB 3213. We conclude that at least this $X$. citri pv. bilvae strain does not have a $X$. citri pv. citri-type CRISPR/Cas system, which is supported by the absence of CRISPRrelated sequences in its draft genome sequence. Notably, other xanthomonads infecting citrus, such as Xanthomonas citri pv. aurantifolii (strains 1566, FDC1559, FDC1561, FDC1609, ICPB 10535, ICPB 11122) and Xanthomonas euvesicatoria pv. citrumelo (strain F1, synonymous to FL1195) do also not have CRISPR loci, as indicated by the absence of cas genes and CRISPR arrays in the genome sequences. Hence, CRISPR loci appear to be restricted to $X$. citri pv. citri among citrus-infecting xanthomonads and our results demonstrate that the cas 1 gene is a useful diagnostic marker for the presence or absence of the CRISPR/Cas system and could be used to differentiate citrus pathogens of the genus Xanthomonas.

\section{CRISPRs in X. citri pv. citri are adapted for a simple genotyping based-PCR tool}

Compared to other strains of Xanthomonas, such as $X$. oryzae pv. oryzae [40,41], the CRISPR locus of X. citri pv. citri is rather small. Most strains of $X$. citri pv. citri have only 23 or fewer spacers while strains of $X$. oryzae pv. oryzae have been found to possess between 37 (Xo604) and 77 spacers (Xo21). Consequently, the small size of the $X$. citri pv. citri CRISPR loci allowed using simple conventional PCR to resolve the genetic diversity of different $X$. citri pv. citri strains. The PCR screening revealed considerable size variation of CRISPR loci among strains of $X$. citri pv. citri, suggesting that these loci consist of different numbers of spacer/repeat units due to deletion or acquisition of spacers based on their evolutionary history. Analysis of spoligotypes showed that most $X$. citri pv. citri strains share 23 or fewer spacers except for CFBP 2911, and that the leaderproximal spacer, which corresponds to the most recently acquired spacer, is conserved in most $X$. citri pv. citri strains (Fig. 2). This means that these strains only differ due to loss of one or more of the 23 spacers. The fact that 23 unique sequences built up the repertoire of spacers suggests that this set of strains originated from a common ancestor that harbored all the 23 spacers. Strain CFBP 2852 represents the oldest isolate in our set of strains (Table 3), yet it lacks already spacer Xcc_14. It would be interesting to go further back in time by analyzing herbarium specimen that date back to the 
Table 3 Origin and relevant characteristics of strains used in this study. Pathotype $b$ indicates that this strain belongs to the pathovar Xanthomonas citri pv. bilvae. Pathotype A: wide host range on Citrus and other related genera, worldwide distribution. Pathotype $A^{*}$ : narrow host range: limes (Citrus aurantifolia) and alemow (Citrus macrophylla), limited areas of distribution. Pathotype $A^{w}$ : narrow host range, limes (C. aurantifolia), hypersensitive response on grapefruit

\begin{tabular}{|c|c|c|c|c|c|c|}
\hline No. & Strain & Pathotype & Geographic origin & Isolation host & Year isolated & GenBank acc. no. \\
\hline 1 & NCPPB 3213 & $b$ & India & N/A & 1982 & $\mathrm{CDHIO1}$ \\
\hline 2 & IAPAR306 & A & Brazil & Citrus sinensis & 1997 & AE008923 \\
\hline 3 & $\mathrm{C} 40$ & A & Reunion Island & C. sinensis & 1988 & CCWX01 \\
\hline 4 & CFBP 2852 & A & India & Citrus sp. & $<1958$ & CCWI01 \\
\hline 5 & FDC217 & A & Brazil & C. sinensis & 2003 & CCWY01 \\
\hline 6 & FDC1083 & A & Brazil & Citrus reticulata & 1980 & CCVZ01 \\
\hline 7 & JJ238-10 & A & Maldives Islands & Citrus aurantifolia & 1987 & CCWC01 \\
\hline 8 & JW160-1 & A & Bangladesh & C. aurantifolia & 2000 & CCWH01 \\
\hline 9 & LMG 9322 & A & Florida, USA & C. aurantifolia & 1989 & CCVY01 \\
\hline 10 & NCPPB 3562 & A & India & Citrus limon & 1988 & CCXZ01 \\
\hline 11 & LC080 & A & Mali & C. reticulata $\times$ C. sinensis & 2006 & CCWJ01 \\
\hline 12 & CFBP 2911 & $A^{*}$ & Pakistan & Citrus sp. & 1984 & CCWD01 \\
\hline 13 & JF090-2 & $A^{*}$ & Oman & C. aurantifolia & 1986 & CCWA01 \\
\hline 14 & JF090-8 & $A^{w}$ & Oman & C. aurantifolia & 1986 & CCWB01 \\
\hline 15 & JJ238-24 & $A^{*}$ & Thailand & C. aurantifolia & 1989 & CCVX01 \\
\hline 16 & JK002-10 & $A^{*}$ & Saudi Arabia & C. aurantifolia & 1988 & cCWV01 \\
\hline 17 & JS584 & $A^{*}$ & Iran & Citrus sp. & 1997 & CCWF01 \\
\hline 18 & LD007-1 & A & Mali & C. aurantifolia & 2007 & CDAL01 \\
\hline 19 & NCPPB 3608 & $A^{w}$ & India & C. aurantifolia & 1988 & CCWG01 \\
\hline 20 & LB305 = X2003-3218 & $A^{w}$ & Florida, USA & Citrus sp. & 2003 & CCWL01 \\
\hline 21 & LE020-1 & $A^{*}$ & Ethiopia & C. aurantifolia & 2008 & CCWK01 \\
\hline 22 & LH001-3 & A & Pakistan & Citrus sp. & 2010 & N/A \\
\hline 23 & LH037-1 & A & Senegal & Citrus paradisi & 2010 & CDAS01 \\
\hline 24 & LG117 & A & Bangladesh & Citrus sp. & 2009 & CDAX01 \\
\hline 25 & LB100-1 & A & Seychelles & C. sinensis $\times$ Poncirus trifoliata & 2005 & CDAV01 \\
\hline 26 & 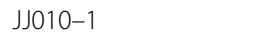 & A & Rodrigues Island & C. aurantifolia & 1985 & CDDV01 \\
\hline 27 & JK004-1 & A & China & Citrus sp. & $<1989$ & CDMR01 \\
\hline 28 & JK148-10 & A & Philippines & Citrus madurensis & 1990 & N/A \\
\hline 29 & CFBP 2900 & A & Japan & Citrus sp. & $<1976$ & N/A \\
\hline 30 & JS582 & $A^{*}$ & Iran & Citrus latifolia & 1997 & CDAP01 \\
\hline 31 & JS555 & $A^{*}$ & Iran & C. paradisi & 1997 & N/A \\
\hline 32 & JS552 & $A^{*}$ & Iran & C. sinensis & 1997 & $\mathrm{~N} / \mathrm{A}$ \\
\hline 33 & LG115 & $A^{w}$ & India & C. aurantifolia & 2007 & CDAY01 \\
\hline 34 & LG116 & $A^{w}$ & India & C. aurantifolia & 2006 & N/A \\
\hline 35 & LG100 & $A^{w}$ & India & C. aurantifolia & 2006 & N/A \\
\hline 36 & JK051 & $A^{*}$ & Saudi Arabia & C. aurantifolia & 1988 & N/A \\
\hline 37 & JK002-14 & $A^{*}$ & Saudi Arabia & C. aurantifolia & 1988 & N/A \\
\hline 38 & JM035-2 & $A^{*}$ & Saudi Arabia & C. aurantifolia & $<1990$ & CDMS01 \\
\hline 39 & JK143-05 & $A^{*}$ & Thailand & C. aurantifolia & $<1990$ & N/A \\
\hline 40 & JK143-09 & $A^{*}$ & Thailand & Citrus sp. & $<1990$ & CDMQ01 \\
\hline 41 & JK143-11 & $A^{*}$ & Thailand & Citrus sp. & $<1990$ & CDMO01 \\
\hline 42 & LD071A & $A^{*}$ & Cambodia & Citrus sp. & 2007 & CCWE01 \\
\hline
\end{tabular}


Table 3 Origin and relevant characteristics of strains used in this study. Pathotype $b$ indicates that this strain belongs to the pathovar Xanthomonas citri pv. bilvae. Pathotype A: wide host range on Citrus and other related genera, worldwide distribution. Pathotype $A^{*}$ : narrow host range: limes (Citrus aurantifolia) and alemow (Citrus macrophylla), limited areas of distribution. Pathotype $A^{w}$ : narrow host range, limes (C. aurantifolia), hypersensitive response on grapefruit (Continued)

\begin{tabular}{|c|c|c|c|c|c|c|}
\hline No. & Strain & Pathotype & Geographic origin & Isolation host & Year isolated & GenBank acc. no. \\
\hline 43 & NCPPB 3607 & $A^{*}$ & India & C. aurantifolia & 1988 & CDAT01 \\
\hline 44 & NCPPB 3615 & $A^{*}$ & India & C. aurantifolia & 1989 & CDAM01 \\
\hline 45 & LE116-1 & $A$ & Mali & C. aurantifolia & 2008 & CDHD01 \\
\hline 46 & LE117-1 & $A$ & Mali & Citrus sp. & 2008 & N/A \\
\hline 47 & LE003-1 & $A^{*}$ & Ethiopia & C. aurantifolia & 2008 & CDAI01 \\
\hline 48 & LE065-1 & $A^{*}$ & Ethiopia & C. aurantifolia & 2008 & N/A \\
\hline 49 & LB302 & $A^{w}$ & Florida, USA & Citrus sp. & 2002 & CDAU01 \\
\hline 50 & LG097 & $A$ & Bangladesh & C. limon & 2006 & CDAK01 \\
\hline 51 & LG102 & $A$ & Bangladesh & Citrus sp. & 2006 & CDAN01 \\
\hline 52 & JS581 & $A^{*}$ & Iran & C. limon & 1997 & CDAW01 \\
\hline 53 & JK048 & $A^{*}$ & Saudi Arabia & C. aurantifolia & 1988 & CDAJ01 \\
\hline 54 & NCPPB 3612 & $A$ & India & C. aurantifolia & 1988 & CDAQ01 \\
\hline 55 & NCPPB 3610 & A & India & P. trifoliata & 1988 & CDAO01 \\
\hline 56 & LE032-1 & $A^{*}$ & Ethiopia & C. aurantifolia & 2008 & N/A \\
\hline 57 & JF090-3 & $A^{*}$ & Oman & C. aurantifolia & 1986 & N/A \\
\hline
\end{tabular}

$\mathrm{N} / \mathrm{A}$, not available

beginning of the twentieth century and to analyse their repertoire of spacers [52].

\section{Correlations among different DNA-based typing methods} Correlation analyses of AFLP versus CRISPR or minisatellite-based typing (MLVA-31) data revealed a fairly good congruence between these methods. We found more AFLP haplotypes (49 haplotypes) and MLVA-31 haplotypes (37 haplotypes) than CRISPR spoligotypes (25 haplotypes). Hence, the AFLP method appears to better resolve the genetic diversity among strains of $X$. citri pv. citri than the two other methods but suffers from technical limitations making interlaboratory comparisons difficult to achieve, a characteristic that precludes a wide use for epidemiosurveillance [17].

In general, strains belonging to a certain spoligotype clade in the CRISPR tree also cluster together in the AFLP tree (Fig. 3). Exceptions were two strains, LH001-3 (spoligotype 23) and LG117 (spoligotype 25), with exceptionally small numbers of spacers, 12 and 8 , respectively, which might explain their misplacement in comparison to the AFLP, MLVA-31 and SNP analyses [17-19]. For instance, strain LH001-3 clusters with strains LD007-1, LE116-1, LE117-1, LH37-1 and NCPPB 3562 in the AFLP analysis. The latter five strains belong to spoligotype 15. Strikingly, a single recombinational event, leading to a deletion of spacers Xcc_11 to Xcc_21, could transform spoligotype 15 into spoligotype 23 of strain LH001-3. Evolutionary speaking, such a scenario would place both strains close to each other. Similarly, both AFLP and spoligotyping cluster strains CFBP 2852, JW160-1, LB100-1 (spoligotype 2), JF090-8, JJ238-10, LG100 (spoligotype 4), NCPPB 3612 (spoligotype 5), NCPPB 3610 (spoligotype 6), and LG116 (spoligotype 7). In addition, AFLP contains as well strain LG117 in this cluster. Again, just two recombinational events, deleting spacers Xcc_01 to Xcc_03 and spacers Xcc_12 to Xcc_23, could transform spoligotype 2 into spoligotype 25 of strain LG117.

Indeed, the used algorithm considers binary information about presence or absence of individual spacers and no software is publicly available to consider the minimal number of necessary mutations for tree construction based on spoligotype data. For example, strain NCPPB 3562 contains spacers Xcc_01 to Xcc_13 and spacers Xcc_19 to Xcc_23. In contrast, strain LH001-3 contains only spacers Xcc_01 to Xcc_10 and spacers Xcc_22 to Xcc $\_23$, i.e. this strain lacks six spacers in comparison to strain NCPPB 3562 (Xcc_11, Xcc_12, Xcc_13, Xcc_19, Xcc_20, Xcc_21), thus resulting in a large apparent distance, which does not necessarily refect the 'true' evolutionary distance. However, incorrect placement of a small number of strains is a common feature of many genotyping techniques. This was observed for a few host-restricted strains (JF090-8 and a few relatives), which clustered with pathotype A genetic lineage 2 strains when assayed by minisatellite-based typing (MLVA-31), whereas SNP analysis from complete genome data unambiguously assigned them to pathotype $\mathrm{A}^{\mathrm{w}}$ $[18,19]$. These strains had been previously erroneously assigned to pathotype $A^{*}$, as they had a Mexican lime- 
restricted host range and AFLP-based methods did not show any close genetic relatedness to other hostrestricted $A^{*}$ or $A^{\mathrm{w}}$ strains [17]. This incorrect placement of a few strains both by spoligotyping and minisatellite-based typing may explain the lower Mantel value between these two techniques, as compared to the values obtained for each of these techniques when compared to AFLP (Table 2).

\section{Distinguishing pathotypes $A$ and $A^{*}$}

Interestingly, pathotype $A$ and pathotype $A^{*}$ strains of our dataset with different citrus host range can be distinguished from each other by the presence or absence of spacer Xcc_06, which corresponds to the first deletion event in the evolution of pathotype $A^{*}$ spoligotypes. Knowledge of pathotype is of importance for disease management and has consequences for regulation measures. However, conventional determination of pathotypes is laborious, as it requires assaying citrus plants. Moreover, some PCR-based techniques failed to accurately identify pathotype $A^{*}$ strains $[53,54]$. Apart from whole genome sequence data, the most straightforward method for distinguishing pathotype $\mathrm{A}^{*}$ from another $X$. citri pv. citri pathotype is currently MLVA-31 (or its derivative MLVA-12) targeting minisatellites $[18,19]$.

We suggest to consider spacer Xcc_06 as a first line of evidence for the identification of pathotype $\mathrm{A}^{*}$ strains using a PCR combining a spacer Xcc_06-specific primer and a primer annealing to the conserved terminator region, which would be a highly discriminatory assay. Analysis of publicly available genomic resources further confirmed the interest of spacer Xcc_06 as a diagnostic marker. Yet, it cannot be ruled out that hitherto undiscovered spoligotypes exist that could undermine such a diagnostic PCR. It is therefore necessary to sequence more CRISPR arrays or genomes, which would (i) help in estimating the discriminatory power of such an approach at a given geographical scale and (ii) allow designing complementary PCR schemes, if necessary.

\section{Origin of spacers}

CRISPR arrays represent a signature of the long history of interactions between bacteria and bacteriophages or other extrachromosomal genetic elements. To understand the evolution of CRISPR loci, it is of interest to know from where the spacer sequences derive. To elucidate their origin, we performed BLASTN searches against the NCBI GenBank. In addition to the hits in the CRISPR loci of completely sequenced $X$. citri pv. citri strains, we found significant hits between spacer sequences and five Xanthomonas bacteriophages, a finding that supports the principal mechanism of CRISPR immune system in bacteria. Homologies with Xanthomonas bacteriophage CP1 (GenBank accession number AB720063) were found for spacers Xcc
36, Xcc_28 and Xcc_25 (Additional file 7: Table S1). Four bacteriophages (CP1, CP2, CP115 and CP122) have been used for classification of $X$. citri pv. citri strains based on their sensitivity to phage for quarantine purposes $[55,56]$. Strains from $X$. citri pv. citri were variable in their sensitivity to bacteriophages CP1 and CP2 [55, 57]. The studies of genomic analysis of bacteriophage $\mathrm{CP} 1$ and $\mathrm{CP} 2$ have reported that the CP1 DNA sequence was detected in the genome sequence of $X$. campestris bacteriophage phiL7 (GenBank accession number EU717894), X. oryzae bacteriophage OP1 (GenBank accession number AP008979) and Xanthomonas bacteriophage Xp10 (GenBank accession number AY299121) [45]. In addition, a sequence in the genomic contig of the Ralstonia-related blood disease bacterium R229 (GenBank accession number FR854082) was related to spacer Xcc_31; this sequence encodes a DNAdependent DNA polymerase with homology to DNA polymerases of the Xanthomonas-specific bacteriophages phiL7, OP1 and Xp10 [58-60]. Possibly, the genomic sequence of the blood disease bacterium R229 corresponds to a prophage with similarity to Xanthomonas-specific bacteriophages. Therefore, spacer Xcc_31 was likely acquired from a bacteriophage. Xanthomonas bacteriophages f20-Xaj and f30-Xaj also matched with several spacers of the 14 unique spacers of strain CFBP 2911 (Additional file 7: Table S1). Those two bacteriophages are closely related to each other and belong to the same clade as $X$. citri pv. citri bacteriophage CP2 [47]. Taken together, this evidence supports the hypothesis that the aforementioned spacers have been acquired from alien DNA most likely derived from bacteriophage CP1 and CP2, which were originally isolated from $X$. citri pv. citri strains [61].

Using less stringent thresholds (E-value smaller than 1 and no minimum criterium with respect to coverage of the query sequence), we also found a match for spacer Xcc_37 in the Xanthomonas bacteriophage CP1, and a few more bacteriophage-related matches for spacers Xcc_31, Xcc_28, Xcc_27, Xcc_11, and Xcc_10 (Additional file 7: Table S1). With even less stringent criteria there are also matches with Xanthomonas-specific bacteriophages for spacers Xcc_34 (bacteriophage CP1), Xcc_ 32 (bacteriophage CP1), Xcc_11 (Streptomyces phage Yaboi), and Xcc_2 (Microbacterium phage MementoMori) (data not shown). However, as demonstrated in Additional file 7: Table S1, relaxing the threshold results in an increased number of matches in genomes of diverse bacteria. Therefore, we cannot conclude that these are bona fide homologs the sequences of which have been altered with the long time since these spacers were acquired, or if these are merely false positives.

Only four of the 23 older spacers matched to sequences in GenBank that did not correspond to the CRISPR arrays of X. citri pv. citri. In all four cases, homology to sequences from integrated prophages or from a 
filamentous bacteriophage was observed. It was surprising that none of the older and conserved 23 spacers matched to a sequence from a bacteriophage genome whereas all the observed hits of the CFBP 2911-specific spacers corresponded to sequences from bacteriophages that have been isolated over the last 50 years. It is not clear whether this observation is merely due to sampling effects or if it reflects the fact that the sources for the 23 old spacers got extinct and only a few of the homologous sequences were vertically inherited and thus preserved in the form of prophages or remnants thereof.

\section{Multiple genetic events have contributed to the CRISPR array diversity within $X$. citri pv. citri}

It is interesting to note that these strains did not acquire new spacers after spacer Xcc_23. Only strain CFBP 2911 acquired 14 new spacers next to the leader sequence, which are not present in any other $X$. citri pv. citri strain that we have analysed (Fig. 2). This finding can be explained by three scenarios. The first explanation that these 14 new spacers were deleted in all $X$. citri pv. citri strains but CFBP 2911 is very unlikely because CFBP 2911 does not represent an ancestral clade at the root of $X$. citri pv. citri phylogeny [18]. Second, it is possible but unlikely as well that none of the 56 strains except for CFBP 2911 was challenged by alien DNA elements, such as bacteriophages or plasmids, since they had acquired spacer Xcc_23. We favor the third hypothesis that the CRISPR immunity system was mutationally inactivated in its ability to acquire new spacers in the ancestor of all $56 X$. citri pv. citri strains in our dataset, yet the CRISPR/Cas system was maintained during evolution as a mechanism of protection against bacteriophage infection. Possibly, a revertant evolved which regained the function of spacer acquisition, giving rise to strain CFBP 2911. Given the important role of the Cas proteins for spacer acquisition in the CRISPR/Cas system, we compared the sequences of the cas gene cluster of strain CFBP 2911 with those of other strains. However, we did not find any differences in the Cas protein sequences between CFBP 2911 and the other strains that could explain the regained CRISPR/Cas activity in strain CFBP 2911 (Additional file 8: Figure S7). Interestingly, csd1/ cas $8 \mathrm{c}$ genes of the majority of strains suffer from a frame-shift mutation due to a short tandem repeat of two base pairs (AG). Yet, strain CFBP 2911 is not the only one that has an intact copy of this gene. Therefore, the reason why strain CFBP 2911 acquired 14 extra spacers is still unclear. For further insight it would be interesting to analyze more strains from the same region as CFBP 2911 (i.e. Pakistan) by assuming that they might have undergone the same evolutionary event(s).

In addition, we found two cases of IS element insertions in CRISPR loci of $X$. citri pv. citri. One insertion occurred in the repeat between spacers Xcc_20 and Xcc_21 (LB302, LB305, LG115 and NCPPB 3608,) and another insertion had occurred in spacer Xcc_18 (LG097) (Fig. 2, Additional file 3: Figure S3, Additional file 4: Figure S4 and Additional file 5: Figure S5). The first four strains originated from India (LG115, NCPPB 3608) and Florida (LB302, LB305). Notably, these strains were all assigned to pathotype $\mathrm{A}^{\mathrm{w}}$ and genetic lineage 3 based on minisatellite typing [19]. Interestingly, the spacer Xcc_14 was deleted from strains, LB302, LB305 and LG115 whereas NCPPB 3608, probably representing the ancestral spoligotype of our dataset, had all 23 spacers. Our results thus further confirm an Indian origin of the $\mathrm{A}^{\mathrm{w}}$ strains from Florida, in agreement with outbreak investigation and previously produced genotyping data $[18,19,62]$. Insertion of IS elements can therefore be another source of polymorphism as frequently observed in the CRISPR locus of $M$. tuberculosis $[63,64]$. Depending on the spoligotyping scheme, insertion of an IS element into either the direct repeat or spacer sequences can influence the spoligotype pattern, resulting in apparent deletion of CRISPR sequence [65]. In such cases, binary data of the spoligotype might be unable to provide sufficient information to accurately establish genotypic relationships among bacterial isolates. This limitation needs to be considered when using spoligotyping data for molecular epidemiological strain tracking and phylogenetic analyses of pathogens [65].

\section{Genealogy of CRISPR spoligotypes}

Since the CRISPR array of all strains originated from a conserved array of 23 spacers, one can use this information to establish an evolutionary trajectory among the observed spoligotypes. To building such an evolutionary pathway one could assume to minimize the number of mutational events that are necessary to connect all spoligotypes with each other. Yet, without additional information it is impossible to be absolutely certain about a given scenario because several alternatives might exist with a similar number of postulated mutation (deletion) events. Here, we took advantage of the availability of genome sequence data for 42 out of the 56 X. citri pv. citri strains, which were used to build a robust phylogenetic tree based on whole genome alignment upon removal of regions with signs of recombination [18]. These data provided information about the evolutionary relationships among 21 spoligotypes. Only spoligotypes $7,13,20,21$, and 23 were not covered by full genome data. In these cases, information was taken from global studies using AFLP and MLVA data [17, 19]. Based on these phylogenetic datasets, which can be considered as evolutionary neutral, we were able to manually build trees for all observed spoligotypes, with one tree representing pathotype $\mathrm{A}$ and another tree representing 
pathotype A* strains (Figs. 4 and 5). Future work including strains representing a larger temporal scale, e.g. from herbarium specimen [52], together with approaches to build time-calibrated phylogenies will help to assess the speed of the molecular CRISPR clock [66].

The phylogenetic trees for pathotype A and $\mathrm{A}^{*}$ strains demonstrate the utility and power of spoligotyping in order to assess the genealogy of bacterial strains. The pathotype A strains fall into two clades that are distinguished by three early deletion events (Fig. 4). One clade consists of two strains from Bangladesh, LG097 and LG102 (spoligotypes 3 and 22, respectively). These two spoligotypes likely derived from a hypothetical intermediate spoligotype (missing link labelled "A" in Fig. 4) that lacks spacers Xcc_03 and Xcc_21. The second clade consists of strains that all lack spacer Xcc_14. Loss of spacer Xcc_14, which is represented by strains from India, Bangladesh and the Seychelles (spoligotype 2), can thus be considered as an early event in the evolution of this clade, possibly in connection with the Indian subcontinent being regarded as a likely area of origin of $X$. citri pv. citri $[19,67]$. Interestingly, this clade contains two spoligotypes that correspond to strains from West Africa, spoligotype 15 (which also contains strain NCPPB 3562 from India) and spoligotype 14 (which also contains three strains from Brazil, FDC2017, FDC1083 and IAPAR306). Since all the West African strains were isolated after 2005 while the other strains have been isolated up to 25 years earlier it is temping to speculate that $X$. citri pv. citri has been introduced in West Africa at least two times, once from the Indian subcontinent and once from South America. Strikingly, this observation is backed by (i) mini- and microsatellite data where spoligotype 15 corresponds to DAPC cluster 2 and spoligotype 14 corresponds to DAPC cluster 1 [21], and (ii) by whole genome data [18].

The pathotype $\mathrm{A}^{*}$ strains fall into two clades that are distinguished by the presence or absence of spacers Xcc_9 and Xcc_10 (Fig. 5). One clade is restricted to strains from Cambodia and Thailand (spoligotypes 16 and 17), which result from an evolutionary pathway that involved at least four spacer/repeat deletion events (spacers Xcc_03, Xcc 08, Xcc_14/Xcc_15, Xcc_19). The other clade shows as well a strong geographic structuring. Spoligotype 18, which only contains strain from Iran, probably evolved by two deletion events (spacers Xcc_03/Xcc_04 and spacers Xcc_18/Xcc_19) from spoligotype 9, which only contains strains from Saudi Arabia. Spoligotypes 12 and 13 are restricted to strains from Ethiopia while spoligotypes 11 and 24 correspond to strains from Pakistan and India,

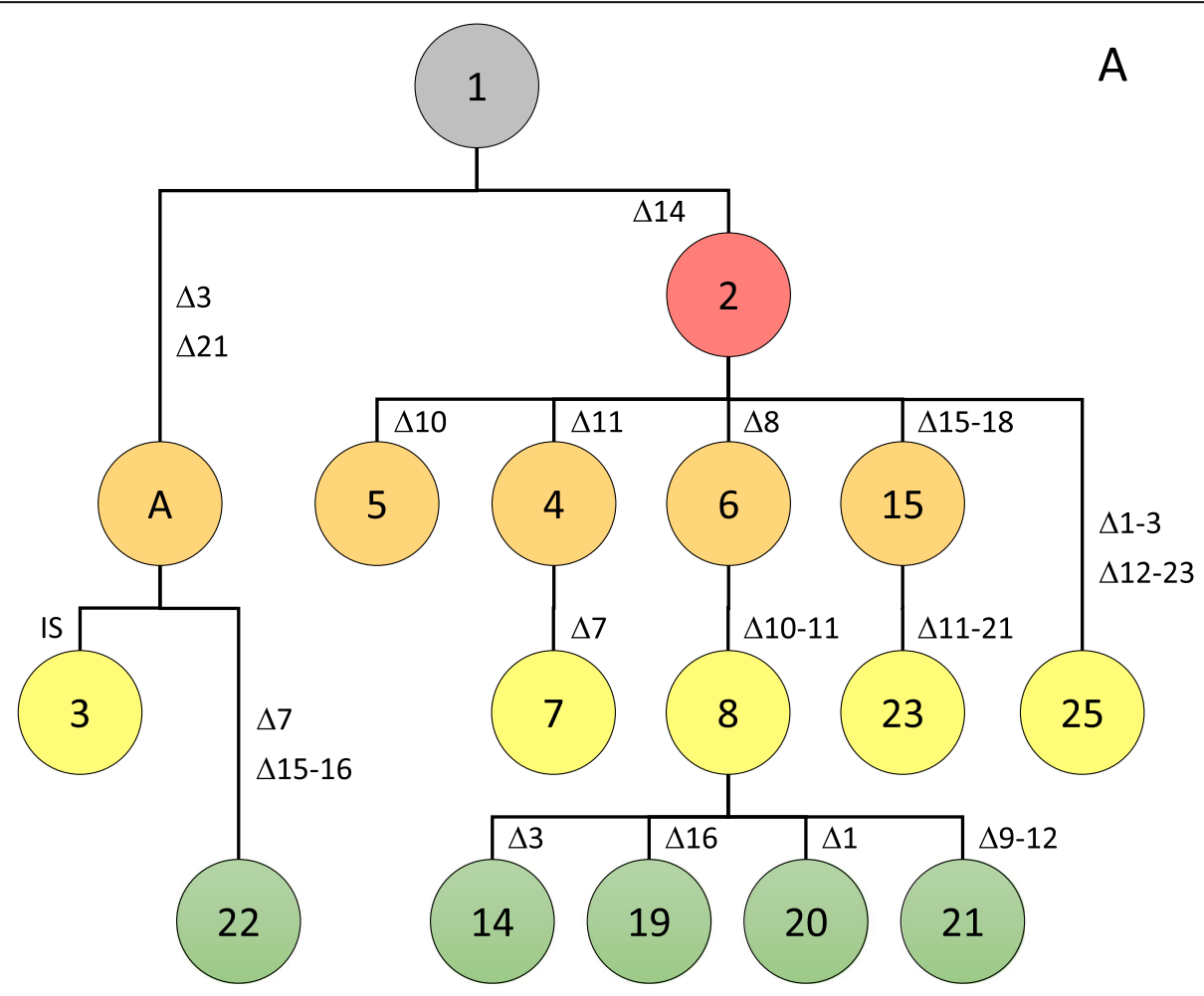

Fig. 4 Genealogy of spoligotypes from pathotype A strains. Postulated mutational events leading to the observed spoligotypes are indicated, starting from the ancestral spoligotype with all 23 spacers (Fig. 2) shown in grey on the top, with the colors indicating the number of events (from one to four events, colored in salmon, orange, yellow, and green, respectively). Numbers of observed haplotypes are indicated in the circles. Characters indicate postulated intermediate haplotypes that were not observed among the 56 analysed strains 


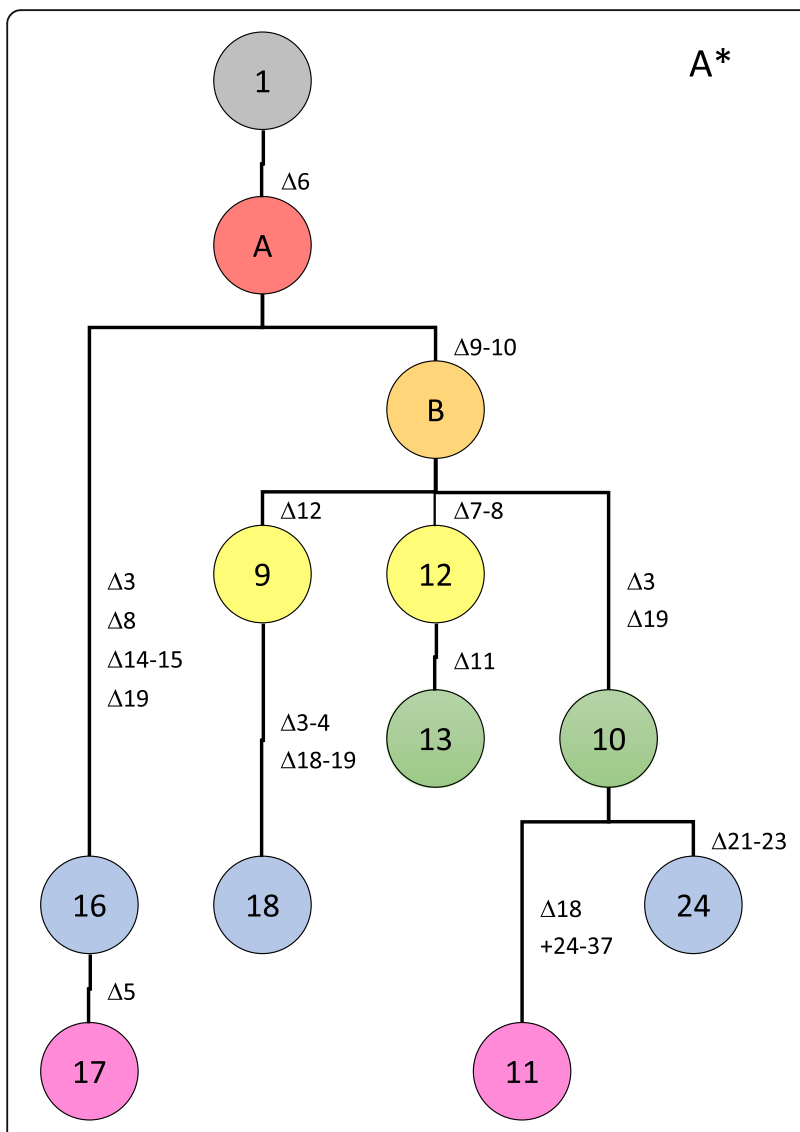

Fig. 5 Genealogy of spoligotypes from pathotype $A^{*}$ strains. Postulated mutational events leading to the observed spoligotypes are indicated, starting from the ancestral spoligotype with all 23 spacers (Fig. 2) shown in grey on the top, with the colors indicating the number of events (from one to six events, colored in salmon, orange, yellow, green, blue and purple, respectively). Numbers of observed haplotypes are indicated in the circles. Characters indicate postulated intermediate haplotypes that were not observed among the 56 analysed strains

respectively, with their ancestral spoligotype 10 consisting of strains from India, Oman and Saudi Arabia. These findings are consistent with previous minisatellite and whole genome sequence analyses [18, 19].

Five of the seven pathotype $\mathrm{A}^{\mathrm{w}}$ strains have been sequenced and allow as well their phylogenetic reconstruction [18]. Strain JF090-8 from Oman (1986) diverged early and its spoligotype 4 can be considered as the ancestor of spoligotype 7, which underwent a subsequent deletion of spacer Xcc_7 (strain LG116 from India, 2006). Spoligotype $1^{*}$, as represented by strain NCPPB 3608 from India (1988) and which contains all 23 ancestral spacers, can be considered as the founder of a distinct clade which is characterized by the acquisition of an IS element between spacers Xcc_20 and Xcc_21. Genomic data indicate that strains LG115 (India, 2007), LB302 (Florida, USA, 2002) and LB305 (Florida, USA, 2003), corresponding to spoligotype $2^{*}$, are descendants of a spoligotype-1* strain that underwent a deletion of spacer Xcc_14 [18]. Therefore and because of their geographic separation it is likely that the deletion of spacer Xcc_14 in spoligotypes $2 *$ and 4 were independent events; hence, effects of homoplasy need to be considered when drawing conclusions from spoligotyping. Nevertheless, we conclude that CRISPR elements provide a new and useful framework for the genealogy of the citrus canker pathogen $X$. citri pv. citri.

\section{Conclusions}

This study provides the necessary information to set up a spoligotyping scheme and a spoligotyping database for $X$. citri pv. citri, similar to the well-established spoligotyping scheme for M. tuberculosis [37]. It demonstrated the advantages and disadvantages of a CRISPR-based typing method. In order to facilitate future work and comparisons we have deposited all CRISPR typing data in the MLVAbank under the name "Xanthomonas_citri CRISPR" (http://www.biopred.net/MLVA/) [68]. In accordance with previous studies [28, 42], we confirmed that CRISPR-based typing can be an efficient and robust method to study the evolution of bacterial isolates and to resolve the phylogenetic relationship among strains. We confirmed that CRISPR loci can differ among strains due to bacteriophage exposure, IS element insertion and intralocus recombination leading to loss of spacer/repeat units, thus giving a valuable typing tool as well [42]. Moreover, the CRISPR-based typing method is easier to perform and more reproducible than AFLP and rep-PCR methods since it can be performed with a simple conventional PCR approach and results in robust binary data.

Genotyping-based surveillance is informative for assessing the geographical expansion of plant pathogenic bacteria, their prevalence, and to identify new strains, especially in the case of regulated pathogens such as $X$. citri pv. citri. We therefore consider our new typing method as a valuable tool for further studies and conclude that, if complete genome sequence data cannot be made available, a combined use of minisatellite and CRISPR-based typing, two techniques combining overall fairly good phylogenetic signals, discriminatory power and portability, should be preferred for placing strains associated with new outbreaks in the global diversity of $X$. citri pv. citri. The correct identification of outbreak strains is a critical issue, as there are marked differences in biological features (e.g., host range) and agricultural significance among genetic lineages (in relation with the pathotype classification), which affect the options possibly taken in terms of disease management $[5,62]$.

\section{Methods}

\section{Isolation of genomic DNA}

The collection of $56 X$. citri pv. citri strains used in this study is representative of the worldwide genetic and 
pathological diversity of $X$. citri pv. citri [18]. The strains originated from Asia (Bangladesh, Cambodia, China, India, Iran, Japan, Oman, Pakistan, Philippines, Saudi Arabia and Thailand), Africa (Ethiopia, Mali and Senegal), North America (Florida-USA), South America (Brazil) and some islands in the Indian Ocean (Maldives, Reunion Island, Rodrigues and Seychelles) (Table 3). Genomic DNA of $X$. citri pv. citri and one strain of $X$. citri pv. bilvae were extracted as previously described [18]. The concentration of genomic DNA samples was approximately $500 \mathrm{ng} / \mu \mathrm{l}$. Each DNA was diluted to 20 $\mathrm{ng} / \mu \mathrm{l}$. DNA quantification was done using a nanodrop device (spectrophotometer ND 1000; Labtech France). Purity of DNA was confirmed by $1.0 \%$ agarose gel electrophoresis, stained with ethidium bromide and visualized on a UV transilluminator.

\section{Genomic information}

Genomic information for $86 \mathrm{X}$. citri pv. citri strains is publicly available (without counting doublets), including 31 complete genome sequences (https://www.ncbi.nlm. nih.gov/assembly/?term=Xanthomonas\%20citri\%20pv.\%2 0citri; queried on July 30, 2019). In this study, we have accessed all genome sequences (Additional file 9: Table S2; Additional file 10: Table S3) to screen for the presence of CRISPR loci. Among them, we used the draft genomes of 42 strains out of the 56 strains tested in this study to confirm our PCR amplification data (Additional file 10: Table S3) [18].

\section{PCR amplification}

A primer pair targeting the cas1 gene of several Xanthomonas species (Xanthomonas albilineans, X. citri pv. citri, $X$. oryzae), resulting in an amplicon of $221 \mathrm{bp}$, was designed and used to evaluate the presence of the CRISPR/ Cas system in strains of X. citri pv. citri (Table 4). PCR primers corresponding to the leader and terminator regions of the CRISPR locus were designed based on five genome sequences of $X$. citri pv. citri and expected to amplify the whole of CRISPR array (Table 4; Additional file 11: Figure S8A). In cases where we could not amplify and/or sequence the full-length CRISPR array, we designed PCR primers corresponding to internal regions of the CRISPR array. Specifically, we designed two forward primers targeting spacers Xcc_21 and Xcc_19 and two reverse primers targeting spacers Xcc_18 and Xcc_02, counting from the terminator of the CRISPR locus (Table 4; Additional file 11: Figure S8B).

PCR results on CRISPR loci indicated the presence of an insertion sequence (IS) element within the CRISPR array of a few strains, including NCPPB 3608. Based on genome sequence data, we designed specific primers corresponding to conserved regions of the IS element (Table 4). Several primer combinations were used to determine the position of the IS element and to elucidate the presence and order of CRISPR spacers, e.g., combinations Leader_fw and IS-1_ rev, IS-2_fw and Spacer\#18_rev, IS-2_fw and Terminator rev (Additional file 12: Figure S9).

PCR amplifications were performed with a 2720 thermal cycler version 2.08 (Applied Biosystems, USA) in a final volume of $25 \mu \mathrm{l}$ containing $10 \mathrm{mM}$ Tris- $\mathrm{HCl}$ (pH 8.5), $50 \mathrm{mM} \mathrm{KCl}, 1.5 \mathrm{mM} \mathrm{MgCl}_{2}, 0.01 \%$ gelatine, $0.2 \mathrm{mM}$ of each dNTP, $10 \mu \mathrm{M}$ of each primer, and 0.25 units of $\mathrm{GoTaq}^{\circ} \mathrm{DNA}$ polymerase (Promega, France). Approximately $20 \mathrm{ng}$ of genomic DNA were added to the PCR mixture. All PCR protocols included an initial denaturation step of $1 \mathrm{~min}$ at $95^{\circ} \mathrm{C}, 30$ cycles of a denaturation step of $2 \mathrm{~min}$ at $94^{\circ} \mathrm{C}$, an annealing step of $30 \mathrm{~s}$ at $55^{\circ} \mathrm{C}$, an elongation step of $2 \mathrm{~min}$ at $72{ }^{\circ} \mathrm{C}$ and a final extension step of $2 \mathrm{~min}$ at $72^{\circ} \mathrm{C}$.

\section{DNA purification and sequencing}

If required, PCR amplicons were purified using the commercial QIAquick Gel Extraction kit (QIAGEN, France). All PCR products were sequenced by Beckman Genomic Inc. (UK), with primers used for PCR amplification. In

Table 4 List of oligonucleotides

\begin{tabular}{lll}
\hline Name & Sequence $\left(5^{\prime} \rightarrow 3^{\prime}\right)$ & Purpose \\
\hline Cas1_fw & GCGCGCGGCTGGGCGA & Detection of cas1 gene \\
Cas1_rev & CGGCGTTGCGTCGCC & \\
Leader_fw & TCACGGGGTCGCATGAC & PCR amplification of CRISPR array \\
Terminator_rev & CTCGTCAGCGTCCGGCTG & \\
Spacer\#19_fw & CGAGCGCATCGATGACGG & PCR amplification of internal region \\
Spacer\#21_fw & TCGGGTTCGGGATGTGC & of the CRISPR array \\
Spacer\#02_rev & CCGGGACGGCGACGAAC & \\
Spacer\#18_rev & CGTCGCTGTCGGTGGCAC & PCR amplification of internal region of \\
IS-1_rev & ACCAGCGCCAGCAGCGG & the CRISPR array next to an IS element \\
IS-2_fw & GCCGACCTGATGATGCA & \\
\hline
\end{tabular}


cases were the PCR amplicon could not be completely sequenced by the PCR primers, amplicons were resequenced using internal primers corresponding to the spacers Xcc_21, Xcc_19, Xcc_18 and Xcc_02, depending on the missing CRISPR regions.

\section{Bioinformatic and statistical analyses}

The obtained DNA sequences were edited and assembled using the CAP 3 program [69], using default parameters. CRISPR spacers and repeats were identified using CRISPRCasFinder (https://crisprcas.i2 bc.paris-saclay.fr/CrisprCasFinder/Index) [25] (Table 1). CRISPR spacers and repeats were annotated on the $X$. citri pv. citri sequences using Artemis Release 17.0.1 (http://www.sanger.ac.uk/science/tools/artemis/ ) [70]. To compare the CRISPR loci of the $56 \mathrm{X}$. citri pv. citri strains, we represented the spacers by different colors, an approach that was called "spacers crawling" in a similar study on E. amylovora [42]. To elucidate the origin of spacer sequences, we performed BLASTN searches in the non-redundant NCBI database (https://blast.ncbi.nlm.nih.gov/Blast. cgi), using the following parameters: E-value threshold 0.1 , word size 7 , default mismatch and gap penalties (i.e. match/mismatch scores: 2, - 3; gap costs: 5 for existence, 2 for extension), no filter for low complexity regions. Only hits with at least $90 \%$ coverage were retrieved. Hits in eukaryotic organisms were excluded. For IS element identification, the IS-Finder database (https://www-is.biotoul.fr/) was used.

In order to compare the resolution and discriminatory power of CRISPR typing with other typing methods, MLVA-14 (microsatellite), MLVA-31 (minisatellite) and AFLP genotyping data were retrieved from our previous studies $[17,19,21]$. The discriminatory power of MLVA-14, MLVA-31, AFLP and CRISPR was calculated based on Hunter's index (D) [71]. Distance matrices of each genotyping method were compared with a Mantel test using the 'CADM.Post' functions of 'APE' package (9999 permutations) in $R$ [72].

\section{Comparison of distance tree analysis between AFLP and CRISPR typing}

AFLP data used for comparison were derived from a previous study [17]. In order to produce a distance tree for 56 strains, a presence/absence matrix was produced based on the distribution of the polymorphism of fragment for AFLP and the distribution of CRISPR spacers for CRISPR typing, respectively. These matrices were analyzed with the DendroUPGMA program (http://genomes.urv.es/UPGMA/ ) using the Dice similarity coefficient and the UPGMA (Unweighted Pair Group Method with
Arithmetic Mean) method [73]. The FigTree program was used to visualize the distance tree map (version 1.4.2; http://tree.bio.ed.ac.uk/software/figtree/).

\section{Supplementary information}

Supplementary information accompanies this paper at https://doi.org/10. 1186/s12864-019-6267-z.

Additional file 1: Figure S1. PCR amplification of a 220-bp cas 1 gene fragment from strains of $X$. citri pv. citri. $M$, molecular weight marker (1-kb ladder, Promega); $n$, negative control (PCR reaction without template DNA). A, strains no. 1-22 of Table 3; B, strains no. 23-44 of Table 3; C, strains no. 45-57 of Table 3 . The red box indicates $X$. citri pv. bilvae strain NCPPB 3213.

Additional file 2: Figure S2. $P C R$ amplification of CRISPR arrays from $X$. citri pv. citri. $M$, molecular weight marker ( $\lambda$ DNA/EcoRI + HindIII, Promega); $n$, negative control (PCR reaction without template DNA). A, strains no. 1-20 of Table 3; B, strains no. 21-40 of Table 3; C, strains no. 41-57 of Table 3.

Additional file 3: Figure S3. Structure of the CRISPR array of $X$. citri $p v$. citri strain NCPPB 3608. Red characters indicate direct repeat sequences, with SNPs underlined. Blue characters indicate spacer sequences. $6 \mathrm{bp}$ (tgaaac) in green boxes represent the target site duplication. Pink boxes represent the inverted repeats (28 bp). Blue boxes represent base pairs that do not match within the inverted repeats.

Additional file 4: Figure S4. Structure of the CRISPR array of $X$. citri $p v$. citri strains LB302, LB305 and LG115. Red characters indicate direct repeat sequences, with SNPs underlined. Blue characters indicate spacer sequences. $6 \mathrm{bp}$ (tgaaac) in green boxes represent the target site duplication. Pink boxes represent the inverted repeats (28 bp). Blue boxes represent base pairs that do not match within the inverted repeats.

Additional file 5: Figure S5. Structure of the CRISPR array of $X$. citri $p v$. citri strain LG097. Red characters indicate direct repeat sequences, with SNPs underlined. Blue characters indicate spacer sequences. 6 bp (cctgca) in green boxes represent the target site duplication. Pink boxes represent the inverted repeats ( $28 \mathrm{bp}$ ). Blue boxes represent base pairs that do not match within the inverted repeats. Spacer Xcc_18*: 4 bp, indicated by dashes, are deleted due to the IS element insertion.

Additional file 6: Figure S6. PCR amplification of spacer/repeat units next to the IS element of five $X$. citri pv. citri strains. $M$, molecular weight marker (1-kb ladder, Promega); $n$, negative control (PCR reaction without template DNA). Lanes 2-7, primer combination Leader_fw and IS-1_rev; lanes 9-14, primer combination IS-2_fw and Spacer\#18_rev.

Additional file 7: Table S1. BLASTN database searches for spacerrelated sequences at NCBI GenBank.

Additional file 8: Figure S7. Multiple sequence alignments of the seven cas gene open reading frames, which were retrieved from the corresponding GenBank files (Table 3).

Additional file 9: Table S2. List of full-length genome resources used in this study.

Additional file 10: Table S3. List of draft genome resources used in this study.

Additional file 11: Figure S8. Primer design for PCR amplification of the CRISPR array from $X$. citri pv. citri. A, amplification of the full-length CRISPR arrays using primers Leader_fw and Terminator_rev. B, amplification to internal regions of the CRISPR arrays using spacer-specific primers. Forward primers are shown as red rectangles with an arrow, reverse primers are represented by blue rectangles with an arrow.

Additional file 12: Figure S9. Primer design for $P C R$ amplification of CRISPR regions adjacent to an IS element. A, primer combinations used for strains LB302, LB305, LG115 and NCPPB 3608; B, primer combinations used for strain LG097. Forward primers are shown as red rectangles with an arrow, reverse primers are represented by blue rectangles with an arrow. The yellow triangle indicates the leader sequence and the red triangle indicates the terminator sequence. Deep blue rectangles indicate 
CRISPR repeats. CRISPR spacers are represented by green diamonds. Spacers are numbered from 1 to 23 , starting with the terminator proximal spacer, which presumably represents the oldest spacer. Orange rectangles indicate IS elements.

\section{Abbreviations}

AFLP: Amplified fragment length polymorphism; BLAST: Basic local alignment search tool; CRISPR: Clustered Regularly Interspaced Short Palindromic Repeats; DAPC: Discriminant analysis of principal components; MLVA: Multilocus VNTR analysis; NCBI: National Center for Biotechnology Information; NGS: Next generation sequencing; rep-PCR: Repetitive elementpolymerase chain reaction; RFLP: Restriction fragment length polymorphism; SNP: Single-nucleotide polymorphism; UPGMA: Unweighted pair group method with arithmetic mean; VNTR: Variable-number of tandem-repeats

\section{Acknowledgements}

LG, CV and OP acknowledge support from The European Regional Development Fund (ERDF) and Région Réunion.

\section{Authors' contributions}

Conceived and designed the experiments: LG, OP and RK. Performed the experiments and acquired the data: $K J, A M B, N A R$, and LP. Run computational predictions and bioinformatic analyses: KJ, LMR and RK. Analysed and interpreted the data: LP, LG, CV, OP and RK. Wrote the manuscript: KJ and RK. Revised and approved the manuscript: KJ, LG, CV, OP and RK. All authors read and approved the final manuscript.

\section{Funding}

This study was supported by grants from the French Agence Nationale de la Recherche (ANR-2010-BLAN-1723). LP was supported by the French Direction Générale de l'Armement (2011 60 091). The funding sources had no input into the study design or analysis and interpretation of outcomes.

\section{Availability of data and materials}

All CRISPR typing data have been deposited in the MLVAbank under the name "Xanthomonas_citri_CRISPR" (http://www.biopred.net/MLVA/).

\section{Ethics approval and consent to participate}

Not Applicable.

\section{Consent for publication}

Not Applicable.

\section{Competing interests}

The authors declare that they have no competing interests.

\section{Author details}

${ }^{1}$ IRD, Cirad, Université de Montpellier, IPME, Montpellier, France. ${ }^{2}$ Present address: Current address: Department of Plant Pathology, University of Florida, Gainesville, FL 32611, USA. ${ }^{3}$ Present address: Laboratoire de Biologie et de Pathologie Végétales, Université de Nantes, Nantes, France. ${ }^{4}$ Present address: Department of Civil and Environmental Engineering, Georgia Institute of Technology, Atlanta, GA 30332, USA. ${ }^{5}$ CIRAD, UMR PVBMT, 97410 Saint Pierre, La Réunion, France. ${ }^{6}$ CIRAD, UMR BGPI, 34398 Montpellier, France.

Received: 31 July 2019 Accepted: 6 November 2019 Published online: 02 December 2019

\section{References}

1. Jacques MA, Arlat M, Boulanger A, Boureau T, Carrère S, Cesbron S, et al. Using ecology, physiology, and genomics to understand host specificity in Xanthomonas. Annu Rev Phytopathol. 2016;54:163-87.

2. Hayward AC. The host of Xanthomonas. In: Swings JG, Civerolo EL, editors. Xanthomonas. London: Chapman \& Hall; 1993. p. 1-119.

3. Leyns F, De Cleene M, Swings JG, De Ley J. The host range of the genus Xanthomonas. Bot Rev. 1984:50:308-56.

4. Gottwald TR, Sun X, Riley T, Graham JH, Ferrandino F, Taylor EL. Georeferenced spatiotemporal analysis of the urban citrus canker epidemic in Florida. Phytopathology. 2002;92(4):361-77.
5. Graham JH, Gottwald TR, Cubero J, Achor DS. Xanthomonas axonopodis pv. citri: factors affecting successful eradication of citrus canker. Mol Plant Pathol. 2004;5(1):1-15.

6. Gottwald TR, Irey M. Post-hurricane analysis of citrus canker II: predictive model estimation of disease spread and area potentially impacted by various eradication protocols following catastrophic weather events. Online. Plant Health Progress. 2007. https://doi.org/10.1094/PHP-2007-0405-01-RS.

7. Patel MK, Allayyanavaramath SB, Kulkarni YS. Bacterial shot-hole and fruit canker of Aegle marmelos Correa. Curr Sci. 1953;22:216-7.

8. Gabriel DW, Kingsley MT, Hunter JE, Gottwald T. Reinstatement of Xanthomonas citri (ex Hasse) and X. phaseoli (ex Smith) to species and reclassification of all X. campestris pv. citri strains. Int. J Syst Bacteriol. 1989; 39(1):14-22.

9. Bui Thi Ngoc L, Vernière $C$, Jouen $E$, Ah-You N, Lefeuvre $P$, Chiroleu F, et al. Amplified fragment length polymorphism and multilocus sequence analysis-based genotypic relatedness among pathogenic variants of Xanthomonas citri pv. citri and Xanthomonas campestris pv. bilvae. Int. J. Syst. Evol. Microbiol. 2010;60(3):515-25.

10. Constantin EC, Cleenwerck I, Maes M, Baeyen S, Van Malderghem C, De Vos $P$, et al. Genetic characterization of strains named as Xanthomonas axonopodis pv. dieffenbachiae leads to a taxonomic revision of the $X$. axonopodis species complex. Plant Pathol. 2016;65(5):792-806.

11. Stall RE, Civerolo EL. Research relating to the recent outbreak of citrus canker in Florida. Annu Rev Phytopathol. 1991;29:399-420.

12. Vernière $C$, Hartung JS, Pruvost $O P$, Civerolo EL, Alvarez AM, Maestri $P$, et al. Characterization of phenotypically distinct strains of Xanthomonas axonopodis pv. citri from Southwest Asia. Eur J Plant Pathol. 1998;104(5):477-87.

13. Sun X, Stall RE, Jones JB, Cubero J, Gottwald TR, Graham JH, et al. Detection and characterization of a new strain of citrus canker bacteria from key/ Mexican lime and alemow in South Florida. Plant Dis. 2004;88(11):1179-88.

14. Leite RP Jr, Egel DS, Stall RE. Genetic analysis of hrp-related DNA sequences of Xanthomonas campestris strains causing diseases of citrus. Appl Environ Microbiol. 1994;60(4):1078-86.

15. Cubero J, Graham JH. The leucine-responsive regulatory protein (Irp) gene for characterization of the relationship among Xanthomonas species. Int J Syst Evol Microbiol. 2004;54(2):429-37.

16. Schaad NW, Postnikova E, Lacy GH, Sechler A, Agarkova I, Stromberg PE, et al. Reclassification of Xanthomonas campestris pv. citri (ex Hasse 1915) Dye 1978 forms A, B/C/D, and E as X. smithii subsp. citri (ex Hasse) sp. nov. nom. rev. comb. nov., X. fuscans subsp. aurantifolii (ex Gabriel 1989) sp. nov. nom. rev. comb. nov., and $X$. alfalfae subsp. citrumelo (ex Riker and Jones) Gabriel et al., 1989 sp. nov. nom. rev. comb. nov.; X. campestris pv. malvacearum (ex smith 1901) Dye 1978 as X. smithii subsp. smithii nov. comb. nov. nom. nov; $X$. campestris pv. alfalfae (ex Riker and Jones, 1935) dye 1978 as X. alfalfae subsp. alfalfae (ex Riker et al., 1935) sp. nov. nom. rev.; and "var. fuscans" of X. campestris pv. phaseoli (ex Smith, 1987) Dye 1978 as X. fuscans subsp. fuscans sp. nov. Syst Appl Microbiol. 2005;28(6): 494-518.

17. Bui Thi Ngoc L, Vernière $C$, Jarne $P$, Brisse $S$, Guérin $F$, Boutry $S$, et al. From local surveys to global surveillance: three high-throughput genotyping methods for epidemiological monitoring of Xanthomonas citri pv. citri pathotypes. Appl. Environ. Microbiol. 2009;75(4):1173-84.

18. Gordon JL, Lefeuvre P, Escalon A, Barbe V, Cruveiller S, Gagnevin L, et al. Comparative genomics of 43 strains of Xanthomonas citri pv. citri reveals the evolutionary events giving rise to pathotypes with different host ranges. BMC Genomics. 2015;16:1098.

19. Pruvost O, Magne M, Boyer K, Leduc A, Tourterel C, Drevet C, et al. A MLVA genotyping scheme for global surveillance of the citrus pathogen Xanthomonas citri pv. citri suggests a worldwide geographical expansion of a single genetic lineage. PLoS One. 2014;9(6):e98129.

20. Vernière $C$, Bui Thi Ngoc $L$, Jarne $P$, Ravigné $V$, Guérin $F$, Gagnevin $L$, et al. Highly polymorphic markers reveal the establishment of an invasive lineage of the citrus bacterial pathogen Xanthomonas citri pv. citri in its area of origin. Environ. Microbiol. 2014;16(7):2226-37.

21. Leduc A, Traoré YN, Boyer K, Magne M, Grygiel P, Juhasz CC, et al. Bridgehead invasion of a monomorphic plant pathogenic bacterium: Xanthomonas citri pv. citri, an emerging citrus pathogen in Mali and Burkina Faso. Environ. Microbiol. 2015;17(11):4429-42.

22. Barrangou R, Fremaux C, Deveau H, Richards M, Boyaval P, Moineau S, et al. CRISPR provides acquired resistance against viruses in prokaryotes. Science. 2007;315(5819):1709-12. 
23. Horvath P, Barrangou R. CRISPR/Cas, the immune system of Bacteria and Archaea. Science. 2010;327(5962):167-70.

24. Barrangou R, Marraffini LA. CRISPR-Cas systems: prokaryotes upgrade to adaptive immunity. Mol Cell. 2014;54(2):234-44.

25. Grissa I, Vergnaud G, Pourcel C. The CRISPR database and tools to display CRISPRs and to generate dictionaries of spacers and repeats. BMC Bioinformatics. 2007;8:172.

26. Garneau JE, Dupuis ME, Villion M, Romero DA, Barrangou R, Boyaval P, et al. The CRISPR/Cas bacterial immune system cleaves bacteriophage and plasmid DNA. Nature. 2010;468(7320):67-72.

27. Haft DH, Selengut J, Mongodin EF, Nelson KE. A guild of 45 CRISPRassociated (Cas) protein families and multiple CRISPR/Cas subtypes exist in prokaryotic genomes. PLoS Comput Biol. 2005;1(6):e60.

28. Makarova KS, Grishin NV, Shabalina SA, Wolf Yl, Koonin EV. A putative RNAinterference-based immune system in prokaryotes: computational analysis of the predicted enzymatic machinery, functional analogies with eukaryotic RNAi, and hypothetical mechanisms of action. Biol Direct. 2006;1:7.

29. Wiedenheft B, Zhou K, Jinek M, Coyle SM, Ma W, Doudna JA. Structural basis for DNase activity of a conserved protein implicated in CRISPR-mediated genome defense. Structure. 2009;17(6):904-12.

30. Brouns SJ, Jore MM, Lundgren M, Westra ER, Slijkhuis RJ, Snijders AP, et al. Small CRISPR RNAs guide antiviral defense in prokaryotes. Science. 2008; 321(5891):960-4

31. Datsenko KA, Pougach K, Tikhonov A, Wanner BL, Severinov K, Semenova E. Molecular memory of prior infections activates the CRISPR/Cas adaptive bacterial immunity system. Nat Commun. 2012;3:945.

32. Jinek M, Chylinski K, Fonfara I, Hauer M, Doudna JA, Charpentier E. A programmable dual-RNA-guided DNA endonuclease in adaptive bacterial immunity. Science. 2012;337(6096):816-21.

33. Groenen PM, Bunschoten AE, van Soolingen D, van Embden JD. Nature of DNA polymorphism in the direct repeat cluster of Mycobacterium tuberculosis; application for strain differentiation by a novel typing method. Mol Microbiol. 1993;10(5):1057-65.

34. Kamerbeek J, Schouls L, Kolk A, van Agterveld M, van Soolingen D, Kuijper S, et al. Simultaneous detection and strain differentiation of Mycobacterium tuberculosis for diagnosis and epidemiology. J Clin Microbiol. 1997;35(4):907-14.

35. Cowan LS, Diem L, Brake MC, Crawford JT. Transfer of a Mycobacterium tuberculosis genotyping method, Spoligotyping, from a reverse line-blot hybridization, membrane-based assay to the Luminex multianalyte profiling system. J Clin Microbiol. 2004;42(1):474-7.

36. Fabre L, Zhang J, Guigon G, Le Hello S, Guibert V, Accou-Demartin M, et al. CRISPR typing and subtyping for improved laboratory surveillance of Salmonella infections. PLoS One. 2012;7(5):e36995.

37. Brudey K, Driscoll JR, Rigouts L, Prodinger WM, Gori A, Al-Hajoj SA, et al. Mycobacterium tuberculosis complex genetic diversity: mining the fourth international spoligotyping database (SpolDB4) for classification, population genetics and epidemiology. BMC Microbiol. 2006;6:23.

38. Sola C, Abadia E, Le Hello S, Weill FX. High-throughput CRISPR typing of Mycobacterium tuberculosis complex and Salmonella enterica serotype Typhimurium. Methods Mol Biol. 2015;1311:91-109.

39. Shariat N, Dudley EG. CRISPRs: molecular signatures used for pathogen subtyping. Appl Environ Microbiol. 2014;80(2):430-9.

40. Salzberg SL, Sommer DD, Schatz MC, Phillippy AM, Rabinowicz PD, Tsuge S, et al. Genome sequence and rapid evolution of the rice pathogen Xanthomonas oryzae pv. oryzae PXO99 ${ }^{\text {A }}$. BMC Genomics. 2008;9:204.

41. Semenova E, Nagornykh M, Pyatnitskiy M, Artamonova II, Severinov K. Analysis of CRISPR system function in plant pathogen Xanthomonas oryzae. FEMS Microbiol Lett. 2009;296(1):110-6.

42. Rezzonico F, Smits TH, Duffy B. Diversity, evolution and functionality of CRISPR regions in the fire blight pathogen Erwinia amylovora. Appl Environ Microbiol. 2011;77(11):3819-29.

43. McGhee GC, Sundin GW. Erwinia amylovora CRISPR elements provide new tools for evaluating strain diversity and for microbial source tracking. PLOS One. 2012;7(7):e41706.

44. Gétaz M, Krijger M, Rezzonico F, Smits THM, van der Wolf JM, Pothier JF. Genome-based population structure analysis of the strawberry plant pathogen Xanthomonas fragariae reveals two distinct groups that evolved independently before its species description. Microb Genom. 2018;4:7.

45. Ahmad AA, Ogawa M, Kawasaki T, Fujie M, Yamada T. Characterization of bacteriophages Cp1 and Cp2, the strain-typing agents for Xanthomonas axonopodis pv. citri. Appl Environ Microbiol. 2014;80(1):77-85.
46. Dömötör D, Frank T, Rákhely G, Doffkay Z, Schneider G, Kovács T. Comparative analysis of two bacteriophages of Xanthomonas arboricola pv. juglandis. Infect Genet Evol. 2016;43:371-7.

47. Retamales J, Vasquez I, Santos L, Segovia C, Ayala M, Alvarado R, et al. Complete genome sequences of lytic bacteriophages of Xanthomonas arboricola pv. juglandis. Genome Announc. 2016;4(3):e00336-16.

48. Ahern SJ, Das M, Bhowmick TS, Young R, Gonzalez CF. Characterization of novel virulent broad-host-range phages of Xylella fastidiosa and Xanthomonas. J Bacteriol. 2014;196(2):459-71.

49. Tseng YH, Lo MC, Lin KC, Pan CC, Chang RY. Characterization of filamentous bacteriophage phi Lf from Xanthomonas campestris pv. campestris. J Gen Virol. 1990;71(8):1881-4.

50. Deveau H, Garneau JE, Moineau S. CRISPR/Cas system and its role in phagebacteria interactions. Annu Rev Microbiol. 2010;64:475-93.

51. Förster H, McGhee GC, Sundin GW, Adaskaveg JE. Characterization of streptomycin resistance in isolates of Erwinia amylovora in California. Phytopathology. 2015;105(10):1302-10.

52. Li W, Song Q, Brlansky RH, Hartung JS. Genetic diversity of citrus bacterial canker pathogens preserved in herbarium specimens. Proc Natl Acad Sci USA. 2007;104(47):18427-32.

53. Cubero J, Graham JH. Genetic relationship among worldwide strains of Xanthomonas causing canker in citrus species and design of new primers for their identification by PCR. Appl Environ Microbiol. 2002;68(3):1257-64.

54. Lee YH, Lee S, Lee DH, Ji SH, Chang HY, Heu S, et al. Differentiation of citrus bacterial canker strains in Korea by host range, rep-PCR fingerprinting and $16 S$ rDNA analysis. Eur J Plant Pathol. 2008;121(1):97-102.

55. Obata T. Distribution of Xanthomonas citri strains in relation to the sensitivity to phages CP1 and CP2. Ann Phytopathol Soc Jpn. 1974;40:6-13.

56. Wu WC, Lee ST, Kuo HF, Wang LY. Use of phages for identifying the citrus canker bacterium Xanthomonas campestris pv. citri in Taiwan. Plant Pathol. 1993:42:389-95.

57. Goto M, Takahashi T, Messina MA. A comparative study of the strains of Xanthomonas campestris pv. citri isolated from citrus canker in Japan and cancrosis B in Argentina. Jpn J Phytopathol. 1980;46:329-38.

58. Inoue Y, Matsuura T, Ohara T, Azegami K. Bacteriophage OP1, lytic for Xanthomonas oryzae pv. oryzae, changes its host range by duplication and deletion of the small domain in the deduced tail fiber gene. J Gen Plant Pathol. 2006;72(2):111-8.

59. Lee CN, Lin JW, Weng SF, Tseng YH. Genomic characterization of the introncontaining T7-like phage phiL7 of Xanthomonas campestris. Appl Environ Microbiol. 2009;75(24):7828-37.

60. Yuzenkova J, Nechaev S, Berlin J, Rogulja D, Kuznedelov K, Inman R, et al. Genome of Xanthomonas oryzae bacteriophage Xp10: an odd T-odd phage. J Mol Biol. 2003;330(4):735-48.

61. Wakimoto S. Some characteristics of citrus canker bacteria, Xanthomonas citri (Hasse) Dowson, and the related phages isolated from Japan. Ann Phytopathol Soc Jpn. 1967;33:301-10.

62. Schubert TS, Rizvi SA, Sun X, Gottwald TR, Graham JH, Dixon WN. Meeting the challenge of eradicating citrus canker in Florida - again. Plant Dis. 2001; 85(4):340-56.

63. Hermans PW, van Soolingen D, Bik EM, de Haas PE, Dale JW, van Embden JD. Insertion element IS987 from Mycobacterium bovis BCG is located in a hot-spot integration region for insertion elements in Mycobacterium tuberculosis complex strains. Infect Immun. 1991;59(8):2695-705.

64. Mokrousov I, Narvskaya O, Limeschenko E, Otten T, Vyshnevskiy B. Novel IS6110 insertion sites in the direct repeat locus of Mycobacterium tuberculosis clinical strains from the St. Petersburg area of Russia and evolutionary and epidemiological considerations. J Clin Microbiol. 2002; 40(4):1504-7.

65. Warren RM, Streicher EM, Sampson SL, Van der Spuy GD, Richardson M, Nguyen D, et al. Microevolution of the direct repeat region of Mycobacterium tuberculosis: implications for interpretation of spoligotyping data. J Clin Microbiol. 2002;40(12):4457-65.

66. Rieux A, Balloux F. Inferences from tip-calibrated phylogenies: a review and a practical guide. Mol Ecol. 2016;25(9):1911-24.

67. Bansal K, Midha S, Kumar S, Patil PB. Ecological and evolutionary insights into Xanthomonas citri pathovar diversity. Appl Environ Microbiol. 2017; 83(9):e02993-16.

68. Poulin L, Grygiel P, Magne M, Gagnevin L, Rodriguez-R LM, Forero Serna N, et al. New multilocus variable-number tandem-repeat analysis tool for surveillance and local epidemiology of bacterial leaf blight and bacterial leaf 
streak of rice caused by Xanthomonas oryzae. Appl Environ Microbiol. 2015; 81(2):688-98.

69. Huang X, Madan A. CAP3: a DNA sequence assembly program. Genome Res. 1999:9(9):868-77.

70. Rutherford K, Parkhill J, Crook J, Horsnell T, Rice P, Rajandream MA, et al. Artemis: sequence visualization and annotation. Bioinformatics. 2000;16(10):944-5.

71. Hunter PR, Gaston MA. Numerical index of the discriminatory ability of typing systems: an application of Simpson's index of diversity. J Clin Microbiol. 1988;26(11):2465-6.

72. Paradis E, Claude J, Strimmer K. APE: analyses of Phylogenetics and evolution in $R$ language. Bioinformatics. 2004;20(2):289-90.

73. Garcia-Vallvé S, Palau J, Romeu A. Horizontal gene transfer in glycosyl hydrolases inferred from codon usage in Escherichia coli and Bacillus subtilis. Mol Biol Evol. 1999;16(9):1125-34.

\section{Publisher's Note}

Springer Nature remains neutral with regard to jurisdictional claims in published maps and institutional affiliations.

Ready to submit your research? Choose BMC and benefit from:

- fast, convenient online submission

- thorough peer review by experienced researchers in your field

- rapid publication on acceptance

- support for research data, including large and complex data types

- gold Open Access which fosters wider collaboration and increased citations

- maximum visibility for your research: over $100 \mathrm{M}$ website views per year

At $\mathrm{BMC}$, research is always in progress.

Learn more biomedcentral.com/submissions 